\title{
EVALUATING COMPLEX DECISION AND PREDICTIVE ENVIRONMENTS: THE CASE OF GREEN SUPPLY CHAIN FLEXIBILITY
}

\author{
Chunguang BAI ${ }^{1^{*}}$, Joseph SARKIS ${ }^{2}$ \\ ${ }^{1}$ School of Management and Economics, University of Electronic Science and Technology of China, \\ No.2006, Xiyuan Ave, West Hi-Tech Zone, Chengdu, 611731, P.R. China \\ ${ }^{2}$ School of Business, Worcester Polytechnic Institute, 100 Institute Road, Worcester, \\ MA 01609-2280, USA
}

Received 17 August 2016; accepted 14 August 2017

\begin{abstract}
Supply chain flexibility is an important operations strategy dimension for organizations to achieve and maintain competitive advantage. With rising greener customer expectations and increasingly stringent environmental regulations, green supply chains are now viewed as another competitive weapon. Green supply chains are characterized by higher complexity and turbulence. Green supply chain flexibility can aid organizations function in this complex and uncertain environment, yet investigation into this area is very limited. This paper aims contribute to this field by investigating green supply chain flexibility achievement through information systems. This paper introduces a green supply chain flexibility matrix framework. Given the large data needs, as described in the matrix, a novel probability evaluation methodology that can help predict rankings of projects and programs is introduced. The methodology extends a TOPSIS based three-parameter interval grey number (TpGN) approach by incorporating neighborhood rough set theory (RST) to evaluate IS programs' green flexibility support capability. The results of this methodology are more objective and effective for two reasons. (1) The results are predictive rankings based on probability degree instead of the fixed deterministic ranks. (2) Neighborhood rough set theory used in this study can limit loss of information when compared to rough set theory, yet still simplify extensive data sets. This paper also identifies study limitations and future research directions for green supply chain flexibility.
\end{abstract}

Keywords: flexibility, green supply chain, information systems, probability evaluation methodology, rough set, TOPSIS, grey number.

JEL Classification: C02, D70, L25, M15, O14.

${ }^{\star}$ Corresponding author. E-mail: chunguang.bai@gmail.com 


\section{Introduction}

Supply chains and supply chain management have added flexibility as a main operations strategy dimension due to increasingly uncertain, complex, and dynamic business environments (Wu, Tseng, Chiu, \& Lim, 2016; Blome, Schoenherr, \& Rexhausen, 2013; Moon, Yi, \& Ngai, 2012). The complexities and uncertainties are driven by business factors such as shorter product lifecycles, more intense global competition, and technological leaps, but also by environmental sustainability concerns such as rising customer environmental sustainability (greening) expectations and increasingly stringent environmental regulations (Bai, Sarkis, \& Dou, 2015a; Blome, Schoenherr, \& Eckstein, 2014; Swafford, Ghosh, \& Murthy, 2006).

Supply chain flexibility and green supply chain management investments help cope with high levels of uncertainty and complexity to achieve competitive advantage and sustainable development (Bai, Dhavale, \& Sarkis, 2016; Gosling, Purvis, \& Naim, 2010). Using the broader definition of supply chain flexibility (Kumar, V., Fantazy, Kumar, U., \& Boyle, 2006), green supply chain flexibility can be defined as the ability of supply chains to rapidly address customers' dynamic green requirements and increasingly stringent environmental regulations without incurring significant performance degradation. These green supply chain flexibility concerns can be relatively more difficult to manage due to immaturity of most organizations in managing green supply chain functions (Bai \& Sarkis 2017, 2013a).

Agile, resilient supply chains and supply chain flexibility have seen increased scrutiny in the operations and supply chain management literature. Although, there are at least two limitations exhibited in this literature (Tiwari, A. K., Tiwari, A., \& Samuel, 2015; Chandra \& Grabis, 2009). The first limitation that most studies are confined to traditional supply chain or manufacturing flexibility (Merschmann \& Thonemann, 2011), thereby neglecting green dimensions of flexibility. Additional green supply chain complexities, such as multiple environmental and business dimensions and more stakeholder influence, add another uncertainty level to this environment (Bai \& Sarkis, 2010). One objective, and a contribution, of this paper is to further study green supply chain flexibility as a response to additional complexities when greening supply chains.

Another limitation of the existing literature is the lack of evaluation and integration of information systems (IS) to address joint environmental and flexibility performance within supply chains. IS plays important roles in communication and decision making that will aid in supply chain flexibility. Some areas and dimensions that can be aided through IS include changes in customers' needs, delivery dates, products range, storage and transportation (Bai \& Sarkis, 2013b; Swafford, Ghosh, \& Murthy, 2008; Cachon \& Fisher, 2000). This paper specifically focuses on IS as a supply chain enabler to support various green flexibility dimensions and concerns. These dimensions will be delineated and introduced in a broad framework. Thus, achieving our second objective and contribution, integrating and introducing a framework for green IS flexibility dimensions for supply chains.

Organizations may be reluctant to invest in flexibility, due to relatively significant amounts and complex data related to various flexibility measures. It is difficult to identify reliable flexibility data and accurately understand the benefits associated with different levels of flex- 
ibility. The complexity and data size increases when additional greening and environmental factors are incorporated. Decision tools are needed to help deal with big and complex data sets (Bai, Sarkis, Wei, \& Koh, 2012). For this reason we introduce a novel multiple criteria decision making (MCDM) methodology for identification and selection of green IS to improve green supply chain flexibility, an to provide a decision making model for converting complex flexibility data into simple and effective metrics for decision making (Bai \& Sarkis, 2013a). We therefore focus on the evaluation and selection of IS as a organizational capability to improve green supply chain flexibility (Liu, Ke, Wei, \& Hua, 2013). The modeling approach is predictive because it takes into consideration probabilities that the decision ranking of alternatives is in accurate order.

The contributions of this study are threefold. A flexibility theoretic framework for green supply chains is developed using supply chain and operations flexibility research. This flexibility framework, which is represented as a matrix, identifies functional flexibilities and across major closed-loop supply chain processes. Second, a novel probability evaluation methodology integrating TOPSIS, neighborhood rough set theory (neighborhood RST), and three-parameter interval grey number (TpGN) which can evaluate IS programs and provide rankings using probability degrees is introduced. A major challenge is to effectively measure the level of flexibility or provide exact numerical values to express flexibility (Chuu, 2011). Supply chain researchers and practitioners could make use of an effective method that enables a synthetic and fuzzy evaluation of flexibility (Moon et al., 2012). This paper applies three-parameter interval grey numbers (TpGNs) to calculate specific flexibility measures for ranking with probability degrees. And third, this paper applies the probability evaluation methodology and the green supply chain flexibility framework for investigating various IS projects.

To help meet these objectives and contributions the outline of the remainder of this paper begins with Section 1 that provides an overview of green supply chain flexibility, green information systems, flexibility measures and flexibility evaluation models. The basic concepts associated with the TOPSIS method, neighborhood RST, and TpGNs are then introduced in Section 2. A novel methodology that integrates these models and parametric characteristic is introduced with a numerical illustration is presented to evaluate IS programs in Section 3. Sensitivity analysis is performed with implications discussion of the technique presented in Section 4 . The final section with a summary and conclusion incorporates additional discussion and identifies future research directions some of which are based on identified study limitations.

\section{Literature review}

The literature regarding green supply chain flexibility and recent studies on IS related supply chain flexibility is overviewed in this section. A green supply chain flexibility framework based on supply chain and manufacturing flexibility literature is then introduced. Finally, formal models in this area are identified with an overview comparison between existing models and the methodology proposed here. 


\subsection{Green supply chain flexibility}

Flexibility is important for organizations to remain competitive given various uncertainties (Das, 2011; Morlok \& Chang, 2004). Flexibility research can be traced to evaluating advanced manufacturing technologies and their contributions to flexibility (Sethi, A. K. \& Sethi, S. P., 1990; Tamayo-Torres, Gutierrez-Gutierrez \& Ruiz-Moreno, 2014). However, manufacturing flexibility as an internal firm measure is not sufficient to deal with supply chain level risk and uncertainty (Tiwari et al., 2015).

Supply chain flexibility research started to appear in the late 1990s (Fisher, 1997; Vickery, Calantone, \& Dröge, 1999). It has now started to receive increased attention since it has become critical for managing supply chain resiliency and risk (Merschmann \& Thonemann, 2011; Gosling et al., 2010; Stevenson \& Spring, 2007; Tiwari et al., 2015).

Current supply chain flexibility research covers a number of topics including supply chain flexibility definitions and dimensions (Kumar et al., 2006), conceptual models for supply chain flexibility (Duclos, Vokurka, \& Lummus, 2003), supply chain flexibility and performance (Martínez Sánchez \& Pérez Pérez, 2005), planning models incorporating flexibility (Esmaeilikia et al., 2016), designing and modeling flexibility in supply chains (Chandra \& Grabis, 2009), information technologies and systems for supply chain flexibility (White, Daniel, \& Mohdzain, 2005), knowledge transfer and supply chain flexibility (Blome et al., 2014), and supply chain flexibility drivers and enablers (More \& Babu, 2011). Most studies showed that flexibility initiatives were positively related to supply chain agility (Liu et al., 2013) and firm performance (Martínez Sánchez \& Pérez Pérez, 2005).

Much of the literature on flexibility is limited to operational issues in the supply chain and does not specifically address green dimensions. Recently a reverse logistics flexibility framework that "closes-the-loop" as part of a green supply chain perspective has been introduced (Bai \& Sarkis, 2013a). In some of green supply chain decision-making literature flexibility, such as in green supplier selection, has been introduced (Bai \& Sarkis, 2010). Performance measures for green supply chain management have also incorporated flexibility dimensions (Bai et al., 2012). Yet most of these flexibility dimensions focus on economic or operational concerns (Bai \& Sarkis, 2013a).

Supply chain flexibility as a regular operational supply chain dimension may not be sufficient for green supply chains with complex environmental dimensions and operating in more risky and uncertain environments. Given some of the unique characteristics of green supply chains, green flexibility is an important research direction. Using traditional supply chain flexibility (Moon et al., 2012), green supply chain flexibility involves the application of supply chain information and resources according to stakeholder green demands and increasingly stringent environmental regulations.

\subsection{Information systems and green supply chain flexibility}

Information systems and technology are important for supply chain flexibility (Liu et al., 2013; Gosain, Malhotra, \& El Sawy, 2004; Golden \& Powell, 1999). IS and IT (information technology) are enablers for greening of supply chains (Hervani, Helms, \& Sarkis, 2005; Gong, Tan, Pawar, Wong, \& Tseng, 2015). These systems may include advanced planning 
and scheduling (APS), collaborative planning, forecasting and replenishment (CPFR), electronic data interchange (EDI), and enterprise resource planning (ERP) systems (Samuel \& Spalanzani, 2009).

Information systems influence the green supply chain's flexibility by building the capability of collecting, analyzing and disseminating information within the firm and with supply partners in an efficient and effective way (Liu et al., 2013). For example, being aware of a manufacturer's green requests and requirements early in the process using collaborative design software enables suppliers to adjust their operations and supply of materials, communication systems may allow for product design flexibility (Ngai, Chau, \& Chan, 2011). A buyer, through its information system, will be able to access information about the changes happening, such as an environmental incident.

Information systems can incorporate information to support all of the relevant supply chain functions and manage volume flexibility, product mix, schedule flexibility, and overall adaptability (Tippins \& Sohp, 2003). The ability of a supplier to access and determine which production schedules, e.g. greener processes and systems, and renewable resources availability in order to provide a buyer with necessary traceability information and to request adjustments as necessary. This traceability concern allows for identifying problem areas with respect to sustainability early, providing opportunity for alternative planning.

IS flexibility can also aid in re-configuration of a green supply chain (Ngai et al., 2011). When an interruption or environmental incident occurs, IS enables the firm to know both the existing green suppliers and the potential qualified suppliers better, which makes the manufacturer efficient and effective in developing a new buyer-supplier relationship or in strengthening the existing relationship. This aspect improves resilience of a supply chain and reduces risk. IS allows a firm to see which of its suppliers could best meet green needs and which of the firm's production facilities are available for the order (Jin, Vonderembse, Ragu-Nathan, \& Smith, 2014).

Inter-organizational information systems may also include green performance measurement systems for control and management purposes (Hervani et al., 2005). Identifying how well organizations performed through these information systems adds to alternatives and early planning improving the flexibility of green supply chains.

While the benefits of IS for supply chain flexibility are generally acknowledged, there is limited research focusing on how an organization can achieve green supply chain flexibility through selection and implementation of IS. Variations in IS flexibility contributions do occur from either organizational or technological reasons. There is no comprehensive IS which can improve all aspects of supply chain flexibility. Thus, some need to develop a formal model to evaluate and introduce the best IS to achieve green supply chain flexibility performance can prove beneficial for organizations, since these investments in terms of organizational time and resources can be significant. However, most prior studies focus on the evaluation of technical characteristics of IS or information technology infrastructure (Jin et al., 2014), and have not supported a link between IS and green supply chain flexibility. 


\subsection{The dimensions and measures of green supply chain flexibility}

Supply chain flexibility is a complex, multi-dimensional competence, which is problematic to measure and hard to assess (Swafford et al., 2006). The supply chain has many inherent external and internal uncertainties that arise from internal cross-functional and cross-organization relationships (Fayezi, Zutshi, \& O'Loughlin, 2015). Supply chain flexibility has primarily drawn on earlier manufacturing flexibility studies (Vokurka \& O’Leary-Kelly, 2000). Manufacturing flexibility includes internal flexibilities such as process, capacity, operation, machine and re-routing flexibility; and external flexibility including, product, volume, mix, access and delivery flexibility (Naim, Potter, Mason, \& Bateman, 2006). Although the literature attempts to extend the research boundary from a single departmental process to multiple departmental processes, they remain focused on the intra-organizational components and to production environments.

Given that traditional boundaries of the firm are blurring with the growth in supply chain management flexibility research has extended to externally focused processes such as procurement, sourcing, and logistics (Stevenson \& Spring, 2007). Supply chain flexibilities, beyond internal manufacturing flexibilities, may include (1) product flexibility dimensions such as new product introduction, volume, distribution, and access flexibilities (Vickery et al., 1999); (2) logistics and distribution flexibilities; and (3) procurement and sourcing flexibility (Garavelli, 2003; Swafford et al., 2006; and Esmaeilikia et al., 2016). Overall there is still limited agreement on supply chain flexibility dimensions.

Green supply chain flexibility requires even further investigation (Bai \& Sarkis, 2013a). Green supply chain flexibility is a multifaceted concept with at least three major flexibility dimensions and across the four major closed-loop supply chain processes supply, manufacturing, distribution/logistics, and reverse logistics flexibility (Esmaeilikia et al., 2016). This paper offers a framework of green supply chain flexibility "close the loop", making reverse logistics and its flexibility an important part of green supply chains.

Green supply flexibility (GSF) includes purchasing function ability to adjust available green suppliers and to influence suppliers' green materials and services performance and variability (Malhotra \& Mackelprang, 2012). For example, with a broader range of green materials available from suppliers procurer has the ability for finding alternative sources. This alternative sourcing availability helps reduce uncertainty in greener materials or goods flow.

Green manufacturing flexibility (GMF) includes manufacturing function ability to transform acquired resources to manufacture a broader range of green products and services. For example, if a supply chain has the ability to vary green product volumes, to adjust green manufacturing facilities and processes; and to develop greater green products and innovations, it can more effectively meet evolving customer green demand standards (Koste, Malhotra, \& Sharma, 2004).

Green distribution flexibility (GDF) is the distribution function's ability to control movement and storage of materials among supply chain member firms (Swafford et al., 2006). For example, green distribution flexibility may also arise from green transportation alternatives (Bai, Fahimnia, \& Sarkis, 2015b). Having a broader selection of alternative energy vehicles may allow organizations in the distribution network to operate without causing their vehicles 
to be banned due to environmental issues. Similar arguments can be made for having flexibility in delivery modes. Packaging may also require some greening flexibility as well.

Reverse logistics flexibility $(R L F)$ is the reverse logistics function's ability to manage reverse logistics processes in response to external stakeholder requirements (Bai \& Sarkis, 2013a). For example, if a supply chain has the ability to manage more activities including separation, collection, disassembly, and outbound logistics; it might increase its ability to handle uncertainty and lessen channel disruption (Tang \& Tomlin, 2008).

A framework of green supply chain flexibility using various functions of the supply chain and three general managerial dimensions of flexibility, configuration design (Garavelli, 2003), green products (Swafford et al., 2008), and green management (Hervani et al., 2005) is now introduced. First, configuration design flexibility $(C F)$ is the ability to adjust and configure supply chain members to achieve to meet customer green demands. A larger supplier base and constantly redesigning and reconfiguring the supply chain are necessary for flexible sourcing (MendonçaTachizawa \& Giménez Thomsen, 2007). Hence, a flexible supply chain includes a buying firm's ability to redesign the supply network quickly and inexpensively (Garavelli, 2003).

Second, green product flexibility (GPF) is the supply chain's ability to alter green product volume, product mix, and schedule. This category is mainly about green product flexibility across their entire production cycle similar to regular products (Blome et al., 2014). The ability to reduce product leadtime, ensuring production capacity, and providing product variety while fulfilling customer expectations are aspects of this supply chain flexibility (Swafford et al., 2008).

Third, green management processes flexibility (GMF) refers to the supply chain's ability to change green management practices such as adjusting resource consumption, pollution production, green practices, and environmental management systems. Green management capabilities can help disseminate environmentally sound practices throughout the complex network of supply chain by green supply chain practice implementation (Hervani et al., 2005). With changes in green consumption demand and environmental regulations, a supply chain must be able to adjust to cope with those environmentally oriented changes and maintain competitiveness while reducing risk (Bai et al., 2016).

Based on the supply chain flexibility literature (Gligor, Esmark, \& Holcomb, 2015; Yusuf et al., 2014; Das, 2011; Braunscheidel \& Suresh, 2009; Stevenson \& Spring, 2009, 2007; Das, 2011; Slack, 1983), we develop a theoretical green supply chain flexibility framework. This theoretical framework utilizes different green supply chain functions to evaluate the various flexibility dimensions. As can be seen in Table 1 we utilize four major green supply chain functions (each row in Table 1), and three general managerial dimensions of flexibility, configuration design, green products, and green management (each column in Table 1). The theoretical framework shows a number of exemplars and categorizations. Additional functions may be added, but these four core functions are more specific to green supply chains. This green supply chain flexibility framework is intended to be multi-level and multi-dimensional. Each measure in the framework is a specific flexibility attribute for the corresponding function and dimension. Different measures may be used and included depending on industry, company, and product characteristics contingencies. 


\begin{tabular}{|c|c|c|c|c|c|}
\hline \multirow{4}{*}{ 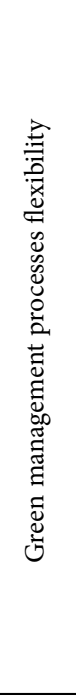 } & 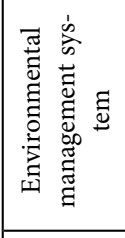 & 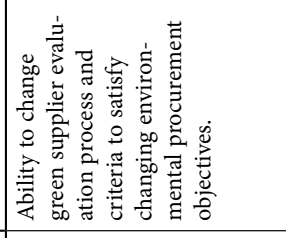 & 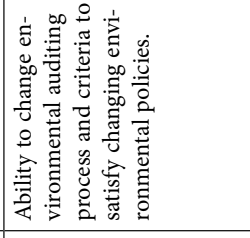 & 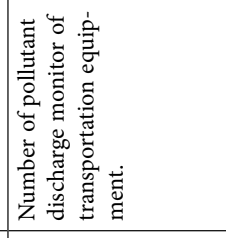 & 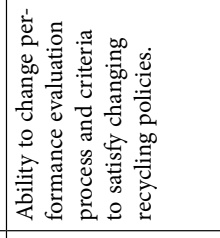 \\
\hline & 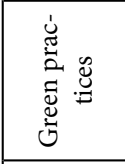 & 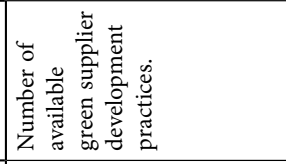 & 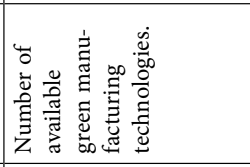 & 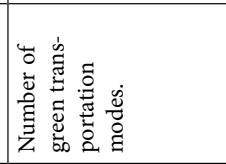 & 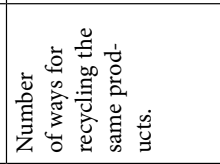 \\
\hline & 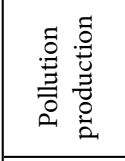 & 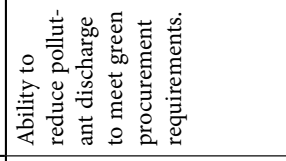 & 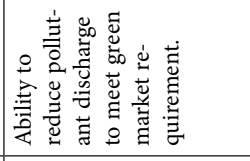 & 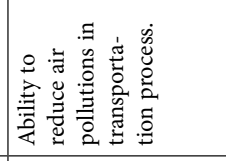 & 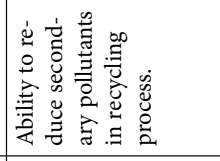 \\
\hline & 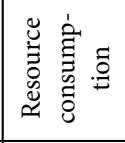 & 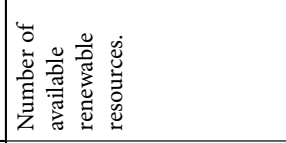 & 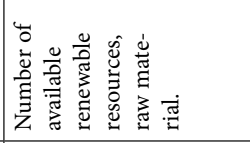 & 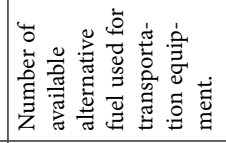 & 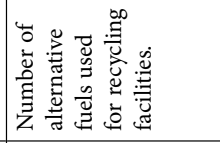 \\
\hline \multirow{5}{*}{ 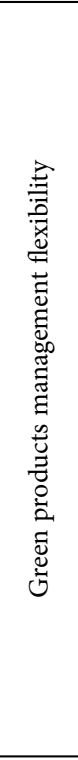 } & 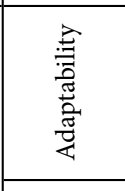 & 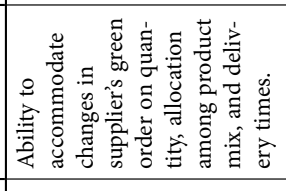 & 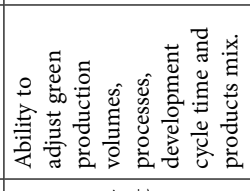 & 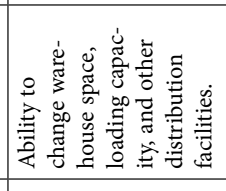 & 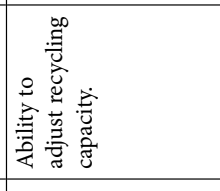 \\
\hline & 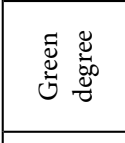 & 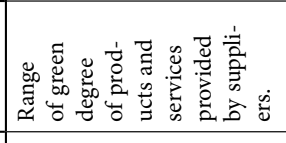 & 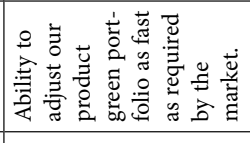 & 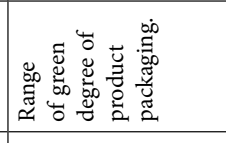 & 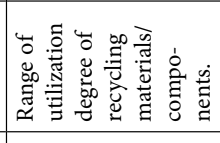 \\
\hline & 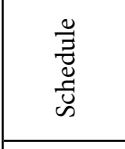 & 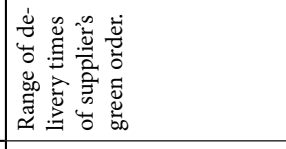 & 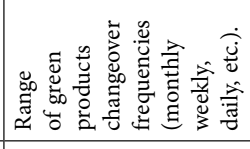 & 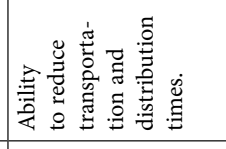 & 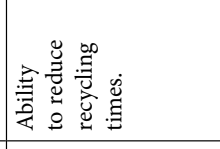 \\
\hline & 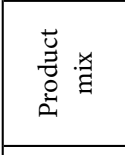 & 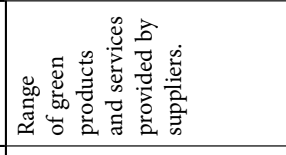 & 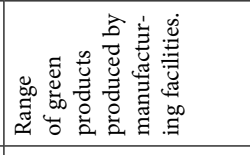 & 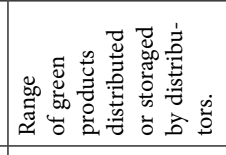 & 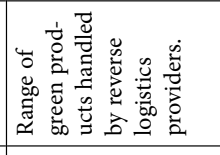 \\
\hline & 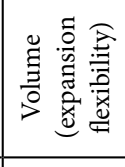 & 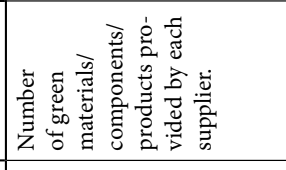 & 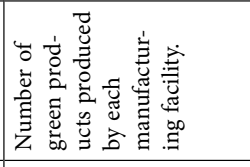 & 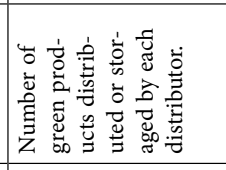 & 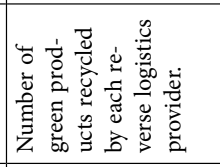 \\
\hline \multirow{2}{*}{ 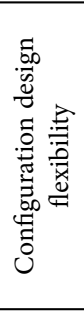 } & 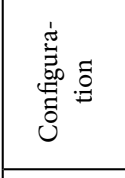 & 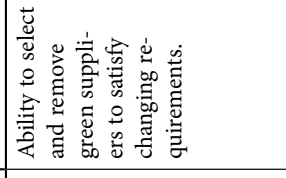 & 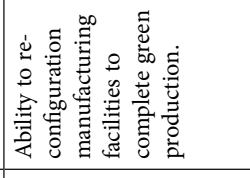 & 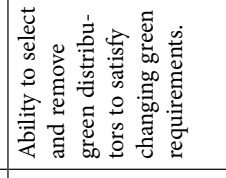 & 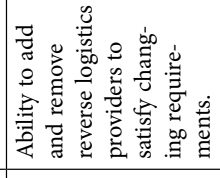 \\
\hline & 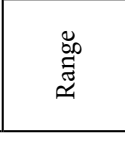 & 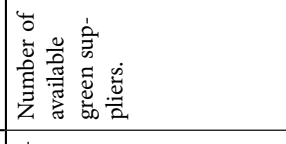 & 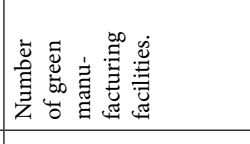 & 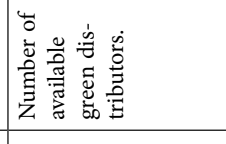 & 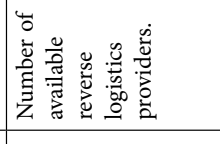 \\
\hline \multicolumn{2}{|c|}{ 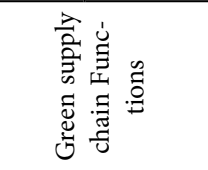 } & 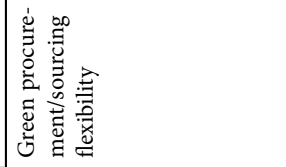 & 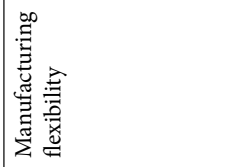 & 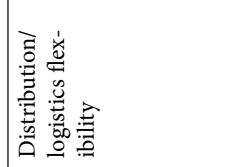 & 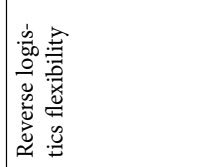 \\
\hline
\end{tabular}




\subsection{Methods for measuring and evaluating flexibility}

Measuring and evaluating flexibility performance in manufacturing can utilize various tools and methods (e.g. Chryssolouris \& Lee, 1992; Seebacher \& Winkler, 2014; Winkler \& Seebacher, 2012). AHP is widely used for tackling flexible manufacturing selection problems due to its simplicity in concept and efficiency in computation (Karsak, 2002). Literature on supply chain flexibility assessment can be broadly classified under empirical, simulation and mathematical models (Tiwari et al., 2015). There is limited literature on evaluating supply chain flexibility using MCDM tools. The analytic network process (ANP) has been used to evaluate the influence of various performance dimensions on the lean, agile and leagile objectives of the supply chain (Agarwal, Shankar, \& Tiwari, 2006). Flexibility in a supply chain has also been evaluated using fuzzy approaches (e.g. Chuu, 2011).

Current MCDM tools are very limited when it comes to the measurement of supply chain level flexibility indices. A highly complex decision environment associated with green supply chain flexibility cause method- and data-related restrictions that hinder practical application of many MCDM methods (Seebacher \& Winkler, 2015). Green supply chain flexibility, especially for maintaining resilience and reducing risk, is an emerging practical and research issue.

IS programs green supply chain flexibility support can be evaluated using the framework defined in Section 1.3 and a new methodology, introduced in this study, that integrates neighborhood RST, TOPSIS and TpGN. Neighborhood RST techniques can help manage large data sets including the multiple dimensions of flexibility performance attributes and measures (Bai et al., 2012). Complex data sets can be reduced to the most effective information (or measures). The results of this methodology are more objective and effective for two reasons. (1) The results are ranks with probability degrees instead of a fixed rank. (2) The neighborhood RST used in this study limits loss of information over basic rough set theory and other methods. An overview of the new methodology is now presented.

\section{A hybrid MCDM approach}

Rough set theory (RST) is a valuable and intuitive approach to overcome methodological development and uncertainty in empirical and decision making research (Bai et al., 2016). RST can evaluate data significance in complex situations for research purposes with no underlying parametric assumptions needed, such as no need to have data that is normally distributed. Three-parameter interval grey numbers, incorporating upper, most likely, and lower values with differing value occurrence probabilities, can better incorporate decision maker uncertainty when compared to traditional grey numbers. The most likely value parameter is introduced to help develop a soft ranking based on TpGNs which is meant to overcome the limitations of hard ranks especially in uncertain environments. TOPSIS is a very popular ranking method and it is easy to integrate with other methods and further supports a soft ranking outcome. To address complex green supply chain flexibility research and modeling challenges, this paper introduces a novel probability evaluation methodology composed of neighborhood RST, TOPSIS with TpGNs. The application of the tool is an evaluation of IS 
programs for supporting green supply chain flexibility whose outcome is a ranking using probability degree.

In this section, notation and expression for of neighborhood RST, TOPSIS, and TpGNs are overviewed. Then, a novel methodology extending neighborhood RST and TOPSIS to deal with the TpGNs is introduced. The final result is a ranking result with probability degrees.

\subsection{Neighborhood rough set theory}

Neighborhood rough set methodology is used to determine information content of flexibility attributes. RST uses similarity classes containing objects that are indiscernible to classify objects (Pawlak, 1982). Neighborhood RST can effectively deal with continuous values, unlike traditional RST that requires discretization of continuous valued data which may cause greater information loss (Bai et al., 2012). A greater set of objects can be included in a neighborhood RST allowing for increased methodological and parametric flexibility. The neighborhood RST used in this study is based on initial developments by ( $\mathrm{Hu}, \mathrm{Yu}, \mathrm{Liu}, \&$ $\mathrm{Wu}, 2008 \mathrm{a}$; $\mathrm{Hu}, \mathrm{Yu}, \& \mathrm{Xie}, 2008 \mathrm{~b})$. Various definitions are now presented.

Definition 1: Let NDS $=(U, C, V)$ be a neighborhood decision system/table, where $U$ is a sample set of objects $U=\left\{x_{1}, x_{2}, \ldots, x_{n}\right\}$, called a universe, our objects in this case are IS technology or programs; $C$ is a nonempty set of attributes $C=\left\{c_{1}, c_{2}, \ldots, c_{\mathrm{m}}\right\}$ to characterize the objects (in this case our attributes will be flexibility attributes); and $V=\bigcup_{a \in C} V_{a}$ indicates the attribute range of an attribute $a$.

Definition 2: Given an arbitrary object $x_{i}, x_{j} \in U$ and $B \subseteq C$, the neighborhood $\delta_{B}\left(x_{i}\right)$ of $x_{i}$ in attribute set $B$ is defined as

$$
\delta_{B}\left(x_{i}\right)=\left\{x_{j} \mid x_{j} \in U, \Delta^{B}\left(x_{i}, x_{j}\right) \leq \delta\right\},
$$

where $\delta$ is a threshold value, and $\Delta$ is a distance function. For $\subseteq x_{1}, x_{2}, x_{3} \in U$, the following four functions should be satisfied:

$$
\begin{aligned}
& \text { (1) } \Delta\left(x_{1}, x_{2}\right) \geq 0 ; \\
& \text { (2) } \Delta\left(x_{1}, x_{2}\right)=0 \text { if and only if } x_{1}=x_{2} \text {; } \\
& \text { (3) } \Delta\left(x_{1}, x_{2}\right)=\Delta\left(x_{2}, x_{1}\right) ; \\
& \text { (4) } \Delta\left(x_{1}, x_{3}\right) \leq \Delta\left(x_{1}, x_{2}\right)+\Delta\left(x_{2}, x_{3}\right) .
\end{aligned}
$$

Definition 3: Given an arbitrary object $x_{i}, x_{j} \in U$, and $v_{i k}$ denote the value of object $i$ on attribute $k$, a Minkowsky distance function between $x_{i}$ and $x_{j}$ may be defined as:

$$
\Delta_{p}\left(x_{i}, x_{j}\right)=\left(\sum_{k=1}^{N}\left|v_{i k}-v_{j k}\right|^{p}\right)^{1 / p}
$$

if $p=1$ it is a Manhattan distance; $p=2$ is a Euclidean distance; and $p=\infty$ is a Chebychev distance (Wilson \& Martinez, 1997). 


\subsection{TOPSIS method}

TOPSIS (technique for order preference by similarity to an ideal solution) is a discrete alternative MCDM tool (Chen \& Hwang, 1992). TOPSIS identifies alternatives with the shortest distance from the improving, ideal solution and the farthest distance from negative-ideal (nadir), solution. The ideal criteria include those that improve as their values increase. Nadir criteria are as they decrease in value. TOPSIS can be expressed in the following steps:

1) Normalize the decision matrix $U=\left(v_{i k}\right)_{n \times m}$ using expression (4):

$$
x_{i k}=\frac{v_{i k}}{\sqrt{\sum_{j=1}^{n} v_{j k}^{2}}}, \quad i=1, \ldots, n ; k=1, \ldots, \mathrm{m} .
$$

2) Adjust the decision matrix with the factor importance weight:

$$
w x_{i k}=w_{k} \times x_{i k} \quad \forall i \in n,
$$

where $w_{k}$ is the importance weight for each factor $k$.

3. Determine the ideal and nadir solution.

$$
\begin{aligned}
I S^{+}= & \left\{w x_{1}^{+}, \ldots, w x_{m}^{+}\right\}= \\
& \left.\left(\max _{i} w x_{i k} \mid k \in I\right),\left(\min _{i} w x_{i k} \mid k \in J\right)\right\}, \\
I S^{-}= & \left\{w x_{1}^{-}, \ldots, w x_{m}^{-}\right\}= \\
& \left.\left(\min _{i} w x_{i k} \mid k \in I\right),\left(\max _{i} w x_{i k} \mid k \in J\right)\right\},
\end{aligned}
$$

where $J$ is associated with averse criteria, $I$ is associated with benefit criteria.

4) Using the n-dimensional Euclidean distance determine the separation measures. The separation measure of each alternative from the ideal solution is expressed in (8):

$$
\mu_{i}^{+}=\sqrt{\sum_{k=1}^{m}\left(w x_{i k}-w x_{k}^{+}\right)^{2}}, i=1, \ldots, n .
$$

The nadir solution separation is calculated as:

$$
\mu_{i}^{-}=\sqrt{\sum_{k=1}^{m}\left(w x_{i k}-w x_{k}^{-}\right)^{2}}, i=1, \ldots, n .
$$

5) The relative closeness each alternative $I S_{i}$ with respect to $I S^{+}$is then calculated by expression (10):

$$
T_{i}=\frac{\mu_{i}^{-}}{\mu_{i}^{+}+\mu_{i}^{-}} .
$$

6) Rank the preference order using values from the previous step. The alternatives are put in decreasing order (Opricovic \& Tzeng, 2004).

\subsection{Three-Parameter Interval Grey Numbers (TpGNs)}

This paper uses TpGNs to model the IS program selection for aiding green supply chain flexibility. TpGNs are better than traditional interval grey numbers to represent the uncertainty of a decision maker's judgment. Traditional interval grey numbers assume an equal 
occurrence probability of values between the upper limits and lower limits (Luo, Wang, \& Song, 2013; Deng, 1989). This characteristic makes traditional grey number unsuitable for real situations and may cause wrong results (Bai et al., 2015b). The TpGN system is then integrated within neighborhood RST and the TOPSIS method.

Definition 4: A TpGN $\otimes x$ is expressed by a value of $(\underline{x}, \tilde{x}, \bar{x})$, where the lower limit value is $\underline{x}$, the most likely value is $\tilde{x}$, and the upper limit value is $\bar{x}$.

When the most likely value is unknown, the TpGN is the same as the traditional interval grey number. When $\underline{x}=\tilde{x}=\bar{x}$, the TpGN $\otimes x$ is reduced to a real number.

Definition 5: Let $\otimes x=(\underline{x}, \tilde{x}, \bar{x})$ and $\otimes z=(\underline{z}, \tilde{z}, \bar{z})$ be two TpGNs. Mathematical functions of the TpGN are defined as (Luo \& Wang, 2012):

$$
\begin{aligned}
& \otimes x+\otimes z=(\underline{x}+\underline{z}, \tilde{x}+\tilde{z}, \bar{x}+\bar{z}) \\
& \otimes x \times \otimes z=[\min (\underline{x} \underline{z}, \underline{x} \bar{z}, \bar{x} \underline{z}, \overline{x z}), \tilde{x} \times \tilde{z}, \max (\underline{x} z \underline{z}, \underline{z}, \bar{x} \underline{z}, \overline{x z})] ; \\
& \otimes x \div \otimes z=[\min (\underline{x} / \underline{z}, \underline{x} / \bar{z}, \bar{x} / \underline{z}, \bar{x} / \bar{z}), \tilde{x} / \tilde{z}, \max (\underline{x} / \underline{z}, \underline{x} / \bar{z}, \bar{x} / \underline{z}, \bar{x} / \bar{z})] .
\end{aligned}
$$

Definition 6: Let $\otimes x=(\underline{x}, \tilde{x}, \bar{x})$ and $\otimes z=(\underline{z}, \tilde{z}, \bar{z})$ be two TpGNs, with $l(\otimes x)=\bar{x}-\underline{x}$, and $l(\otimes z)=\bar{z}-\underline{z}$. The probability degrees for TpGNs are now defined basded on the probability degree of two interval grey numbers (Nakahara, Sasaki, \& Gen, 1992).

$$
P(\otimes x \geq \otimes z)= \begin{cases}\frac{1}{\bar{x}-\underline{z}+\tilde{x}-\tilde{z}} & \underline{x} \geq \bar{z} \\ \frac{\bar{x}}{l(\otimes x)+l(\otimes z)} & \bar{z} \wedge \underline{x}<\bar{z} . \\ 0 & \bar{x} \leq \underline{z}\end{cases}
$$

Where $P(\otimes x \geq \otimes z)$, is a percentage representing the probable value that TpGN $\otimes x$ is bigger than TpGN $\otimes z$. Where $0.5<P(\otimes x \geq \otimes z) \leq 1$ indicates that the TpGN $\otimes x$ dominates TpGN $\otimes z$, and denoted $\otimes x \succ \otimes z$.

Definition 7: A new distance measure is introduced using expression (15):

$$
d(\otimes x, \otimes z)=\alpha \sqrt{(\underline{x}-\underline{z})^{2}}+\beta \sqrt{(\tilde{x}-\tilde{z})^{2}}+(1-\alpha-\beta) \sqrt{(\bar{x}-\bar{z})^{2}},
$$

where $\alpha, \beta$ are weight parameters, $0 \leq \alpha \leq 0.5 ; 0.5 \leq \beta \leq 1 ; \alpha+\beta \leq 1$.

This distance formula treats the most likely value as important as the traditional upper and lower limit values of TpGNs. Expression (15) provides a differential weighting system for each element of the grey number. The differential weight parameter values can incorporate issues such as decision makers' expertise, experience, and risk propensity.

\section{Information systems selection for green supply chain flexibility}

The application of the proposed MCDM for evaluation of IS programs for improving supply chain green flexibility is now illustrated. The proposed methodology is composed of 9 steps, which are presented in detail with the operations explicitly identified.

First, assume that a database of IS programs based on various green flexibility attributes exists (a grey decision system). This system is defined by $T=(U, C, V)$, where $U=\left\{I S_{1}, I S_{2}\right.$, $\left.\ldots, I S_{n}\right\}$ is a set of $n$ alternative IS programs called the universe. $C=\left\{c_{1}, c_{2}, \ldots, c_{m}\right\}$ is a set of $m$ green flexibility attributes. 
For the illustrative case, 15 IS programs, $U=\left\{I S_{\mathrm{i}}, \mathrm{i}=1,2, \ldots, 15\right\}$ are considered. The green flexibility performance the IS programs uses weights across the 11 attributes $C=\left\{c_{j}\right.$, $j=1,2, \ldots, 11\}$. Table 1 provides the attributes that are initially used and are further refined and can be preliminarily reduced. For this illustrative case, the eleven attributes only represent the three dimensions of manufacturing process green flexibility. For the illustrative case there are two configuration design attributes: range and configuration; four green products attributes: volume, product mix, schedule, and adaptability; and five green management attributes: resource consumption, pollution production, green degree, green practices and environmental management system.

\section{Step 1: Determine the Flexibility Performance of each IS Programs}

Green flexibility attributes may have qualitative and quantitative characteristics. As an example, for a quantitative measure configuration design range attribute for IS program 01 can manage up to 4 green manufacturing facilities or processes, most effectively manage 3 green manufacturing facilities or processes, as a minimum deal with 0 facilities or processes. Thus the configuration design range attribute for IS program 01 can be valued $I S_{01 \text { rang }}=(0$, $3,4)$. For a qualitative attribute expert or managerial judgment can be used to evaluate a green flexibility attribute for an IS program. This data may be scaled along a seven linguistic perceptual score range: from "very good" to "very poor". An example data set for the full information decision system is shown in Table 2.

The qualitative scores using linguistic variables can be transformed to normalized grey numbers (see Table 3).

\section{Step 2: Normalize the Information Decision System}

Due to green flexibility attributes in all the later calculations requiring similar scales, this paper introduces a normalization process. The TpGN values are now normalized. Membership functions, expressions (16) (for beneficial valuations) and (17) (for averse evaluations) are initially introduced.

$$
\begin{aligned}
& U\left(\underline{v}_{i j}, \tilde{v}_{i j}, \bar{v}_{i j}\right)=\left(\underline{x}_{i j}, \tilde{x}_{i j}, \bar{x}_{i j}\right)\left\{\begin{array}{l}
0 \text { if } \underline{v}_{i j} \leq \text { Lower, } \\
\underline{x}_{i j} \text { if Lower } \leq \underline{v}_{i j} \leq \text { Upper, } \\
\text { where } \underline{x}_{i j}=\frac{\underline{v}_{i j}-\text { Lower }}{\text { Upper - Lower }} \\
1 \text { if } \underline{v}_{i j} \geq \text { Upper, }
\end{array}\right. \\
& \tilde{x}_{i j}, \bar{x}_{i j} \text { the same calculation process, }
\end{aligned}
$$

where $\left(\underline{v}_{i j}, \tilde{v}_{i j}, \bar{v}_{i j}\right)$ is the specific evaluation value, $\underline{v}_{i j}$ is the minimum value for IS program support, $\tilde{v}_{i j}$ is the best value for IS program support and $\bar{v}_{i j}$ is the maximum value for IS program support.

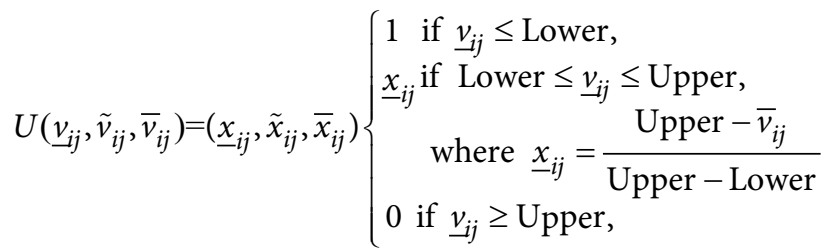

$$
\begin{aligned}
& \tilde{x}_{i j}, \bar{x}_{i j} \text { the same calculation process. }
\end{aligned}
$$




\begin{tabular}{|c|c|c|c|c|c|c|c|c|c|c|c|c|c|c|c|c|}
\hline \multirow{4}{*}{ 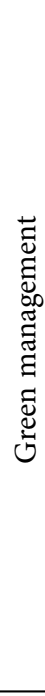 } & 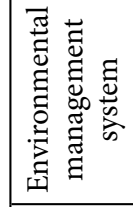 & ט & $\Sigma$ & $\stackrel{p}{>}$ & 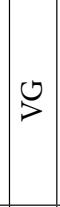 & 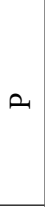 & & & $\stackrel{p}{p}$ & ט & $\stackrel{p}{>}$ & $\stackrel{s}{s}$ & 0 & & & $\stackrel{p}{>}$ \\
\hline & 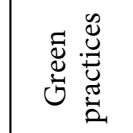 & $\begin{array}{l}0 \\
0 \\
0 \\
0\end{array}$ & $\begin{array}{l}\hat{E} \\
\hat{\omega} \\
\hat{e}\end{array}$ & $\begin{array}{l}0 \\
0 \\
\text { fot } \\
e\end{array}$ & $\begin{array}{l}\hat{\infty} \\
\hat{e} \\
\hat{e}\end{array}$ & $\begin{array}{l}\hat{\sigma} \\
\hat{2} \\
\hat{e}\end{array}$ & $\mid \begin{array}{c}\tilde{r} \\
\hat{2} \\
\hat{e}\end{array}$ & \begin{tabular}{|c|c|}
0 \\
$\hat{s}$ \\
$\hat{e}$ \\
$\hat{e}$
\end{tabular} & $\begin{array}{l}\widehat{\infty} \\
\hat{f} \\
\hat{e}\end{array}$ & $\begin{array}{l}\hat{\sigma} \\
\hat{\hat{e}} \\
\hat{e}\end{array}$ & 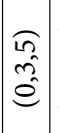 & $\begin{array}{l}\widehat{E} \\
\vec{\approx} \\
\hat{\hat{\theta}}\end{array}$ & 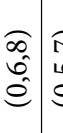 & & & $\begin{array}{l}\text { o } \\
\text { fo } \\
\hat{e}\end{array}$ \\
\hline & 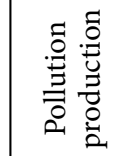 & ט & $\Sigma$ & $\stackrel{p}{>}$ & $\begin{array}{l}0 \\
>\end{array}$ & $a_{1}$ & $\begin{array}{l}0 \\
>\end{array}$ & $\stackrel{p}{>}$ & ט & $\Sigma$ & $\begin{array}{l}0 \\
>\end{array}$ & $\infty$ & 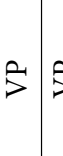 & 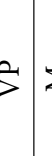 & $\Sigma$ & $\stackrel{9}{\Sigma}$ \\
\hline & 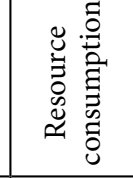 & $\begin{array}{l}0 \\
\text { th } \\
\hat{e}\end{array}$ & $\begin{array}{l}\widehat{E} \\
\hat{\hat{e}}\end{array}$ & $\begin{array}{l}\infty \\
0 \\
0 \\
\hat{e}\end{array}$ & $\begin{array}{l}\widehat{E} \\
\hat{n} \\
\hat{e}\end{array}$ & $\begin{array}{l}0 \\
0 \\
\hat{2} \\
\hat{e}\end{array}$ & $\begin{array}{l}\widehat{\alpha} \\
\hat{\alpha} \\
\hat{e}\end{array}$ & $\begin{array}{l}\hat{\sigma} \\
\hat{\hat{e}} \\
\hat{\hat{\theta}}\end{array}$ & $\begin{array}{l}\sqrt{n} \\
\hat{2} \\
\hat{e}\end{array}$ & 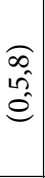 & $\mid \begin{array}{c}\stackrel{f}{f} \\
\hat{m} \\
\hat{e}\end{array}$ & $\begin{array}{l}\hat{\sigma} \\
\hat{n} \\
\hat{e}\end{array}$ & 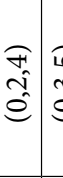 & & & $\begin{array}{l}\hat{A} \\
\hat{m} \\
\hat{e}\end{array}$ \\
\hline \multirow{5}{*}{ 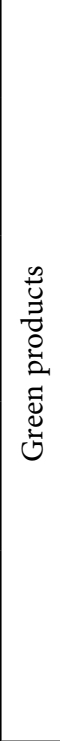 } & 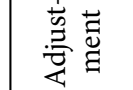 & $\stackrel{>}{>}$ & Dr & $\stackrel{p}{p}$ & 0 & $\Sigma$ & 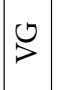 & $\infty$ & $\stackrel{\cup}{>}$ & $\Sigma$ & $\bar{\Sigma}$ & ৩" & $\Sigma$ & $f$ & $\Sigma$ & $\stackrel{0}{\Sigma}$ \\
\hline & 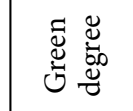 & \) & a & $\stackrel{p}{>}$ & $\stackrel{2}{>}$ & ט & $\Sigma$ & 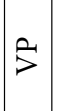 & $\stackrel{\cup}{>}$ & $a_{1}$ & $\begin{array}{l}0 \\
>\end{array}$ & $\stackrel{>}{>}$ & $\stackrel{s}{\circ}$ & 0 & $\Sigma$ & $\stackrel{p}{>}$ \\
\hline & 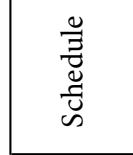 & 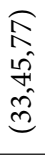 & $\begin{array}{l}\text { त̂ } \\
\hat{\tilde{N}} \\
\tilde{N} \\
\hat{0} \\
\text { d. }\end{array}$ & 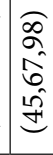 & 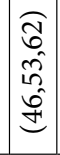 & 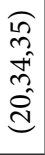 & 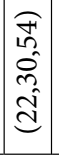 & $\begin{array}{l}\overparen{y} \\
\stackrel{f}{m} \\
\tilde{d} \\
d\end{array}$ & 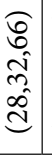 & 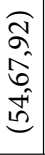 & 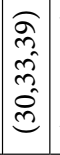 & $\begin{array}{l}\infty \\
\infty \\
0 \\
0 \\
0 \\
0 \\
0\end{array}$ & 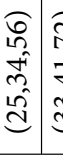 & 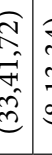 & & 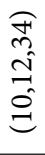 \\
\hline & 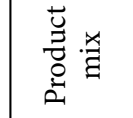 & $\begin{array}{l}\text { Ê } \\
\text { ह̂ } \\
\hat{e}\end{array}$ & $\begin{array}{l}\hat{\sigma} \\
\hat{\hat{e}}\end{array}$ & $\begin{array}{l}\text { r̂ } \\
\hat{2} \\
\hat{e}\end{array}$ & $\begin{array}{l}0 \\
\hat{0} \\
\hat{2} \\
\hat{e}\end{array}$ & $\begin{array}{l}\widehat{\Xi} \\
\hat{0} \\
\hat{\Theta}\end{array}$ & $\left|\begin{array}{l}0 \\
0 \\
0 \\
0 \\
0\end{array}\right|$ & $\begin{array}{c}\hat{\hat{n}} \\
\hat{i n} \\
\hat{e}\end{array}$ & $\begin{array}{l}6 \\
\hat{+} \\
\hat{e}\end{array}$ & $\begin{array}{l}\infty \\
\hat{\infty} \\
\hat{e} \\
\hat{e}\end{array}$ & $\mid \begin{array}{c}\hat{n} \\
m \\
\hat{e} \\
\hat{e}\end{array}$ & 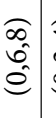 & $\begin{array}{ll}\vec{F} & a \\
\hat{m} \\
\hat{e}\end{array}$ & $\begin{array}{l}\hat{\sigma} \\
\hat{e} \\
\hat{e}\end{array}$ & & $\begin{array}{l}\widehat{n} \\
\hat{s} \\
\hat{e}\end{array}$ \\
\hline & 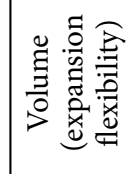 & 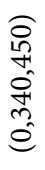 & 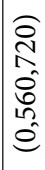 & 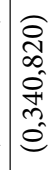 & 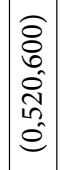 & $\begin{array}{l}\widehat{O} \\
\text {. } \\
0 \\
0 \\
0 \\
0 \\
0\end{array}$ & $\left|\begin{array}{c}0 \\
\infty \\
\infty \\
0 \\
0 \\
0 \\
0 \\
e \\
e\end{array}\right|$ & 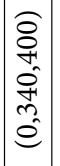 & $\begin{array}{l}\widehat{\sigma} \\
0 \\
0 \\
0 \\
0 \\
m \\
\hat{e}\end{array}$ & $\begin{array}{l}\widehat{o} \\
\infty \\
\hat{0} \\
0 \\
0 \\
0 \\
0\end{array}$ & 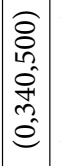 & 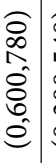 & 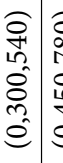 & 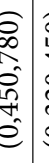 & & 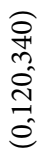 \\
\hline \multirow{2}{*}{ 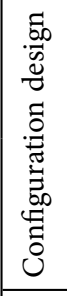 } & 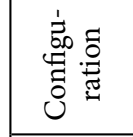 & $\stackrel{>}{>}$ & or & $\stackrel{>}{>}$ & $\Sigma$ & $\stackrel{\xi}{\Sigma}$ & 2 & $\stackrel{p}{>}$ & ט & $\Sigma$ & 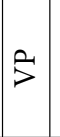 & $\Sigma$ & $\sum_{\Sigma}^{0}$ & . & ט\$? & $\tilde{\Sigma}$ \\
\hline & 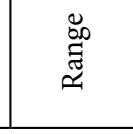 & $\begin{array}{l}\stackrel{f}{f} \\
\hat{\Omega} \\
\hat{e}\end{array}$ & $\begin{array}{l}\hat{\sigma} \\
\hat{\hat{e}} \\
\hat{e}\end{array}$ & $\begin{array}{l}\pi \\
\text { nf } \\
\hat{e}\end{array}$ & $\begin{array}{l}0 \\
\hat{0} \\
\hat{1} \\
\hat{e}\end{array}$ & $\begin{array}{l}\text { fr } \\
\hat{i} \\
\tilde{e}\end{array}$ & \begin{tabular}{|l|}
$\widehat{\alpha}$ \\
$\hat{0}$ \\
$\hat{e}$
\end{tabular} & $\mid \begin{array}{c}\hat{E} \\
\hat{2} \\
\hat{e}\end{array}$ & 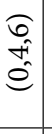 & $\begin{array}{l}\widehat{D} \\
\hat{A} \\
\hat{e}\end{array}$ & 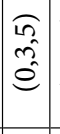 & 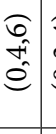 & $\begin{array}{cc}\stackrel{f}{r} & \partial \\
\hat{m} \\
\hat{e}\end{array}$ & 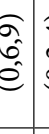 & & $\begin{array}{l}\hat{m} \\
\hat{e}\end{array}$ \\
\hline \multicolumn{2}{|c|}{ 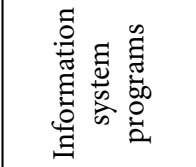 } & 忿 & $\begin{array}{l}\tilde{D} \\
\stackrel{n}{2}\end{array}$ & $\mid \begin{array}{l}\tilde{O} \\
0 \\
0\end{array}$ & $\begin{array}{l}\overrightarrow{0} \\
0 \\
0\end{array}$ & $\begin{array}{l}\text { 怘 } \\
: 0\end{array}$ & 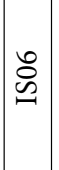 & 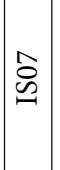 & $\begin{array}{l}\infty \\
0 \\
0 \\
0\end{array}$ & 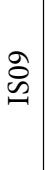 & $\begin{array}{l}\vec{a} \\
\vec{n}\end{array}$ & $\overrightarrow{\vec{n}}$ & 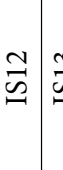 & $\vec{s}$ & 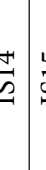 & $\begin{array}{l}\stackrel{n}{\sim} \\
\stackrel{n}{n}\end{array}$ \\
\hline
\end{tabular}


Table 3. The linguistic variables and their corresponding three-parameter interval grey numbers

\begin{tabular}{|l|c|}
\hline \multicolumn{1}{|c|}{ Linguistic variables } & Three-parameter interval grey numbers \\
\hline Very Poor (VP) & $(0,0,0.1)$ \\
\hline Poor (P) & $(0,0.1,0.3)$ \\
\hline Medium Poor (MP) & $(0.1,0.3,0.5)$ \\
\hline Medium(M) & $(0.3,0.5,0.7)$ \\
\hline Medium Good (MG) & $(0.5,0.7,0.9)$ \\
\hline Good (G) & $(0.7,0.9,1.0)$ \\
\hline Very Good (VG) & $(0.9,1.0,1.0)$ \\
\hline
\end{tabular}

For the IS program 01 configuration design range attribute, $I S_{01 \text { rang }}=(0,3,4)$, the normalization using expressions (16) is as follows: $\underline{x}_{11}=\frac{\left|\underline{v}_{11}-v_{1}^{\min }\right|}{\left|v_{1}^{\max }-v_{1}^{\min }\right|}=\frac{|0-0|}{|9-0|}=0$; $\tilde{x}_{11}=\frac{\left|\tilde{v}_{11}-v_{1}^{\min }\right|}{\left|v_{1}^{\max }-v_{1}^{\min }\right|}=\frac{|3-0|}{|9-0|}=0.333 ; \bar{x}_{11}=\frac{\left|\bar{x}_{11}-v_{1}^{\min }\right|}{\left|v_{1}^{\max }-v_{1}^{\min }\right|}=\frac{|4-0|}{|9-0|}=0.444$.

Thus, the normalized value of the TpGN for $I S_{01 \text { rang }}=(0,0.333,0.444)$. This step normalized the original matrix $\left[v_{i j}\right]$ to arrive at a normalized matrix $\left[x_{i j}\right]$ using expressions (16) and (17). The normalization process results in a matrix with all increasing values representing better green flexibility attributes (see Table 4).

\section{Step 3: Compute Green Flexibility Attributes Neighborhood Relational Matrices for}

Similarity measures using the TpGN distance calculation and the neighborhood threshold parameter are used to group sets of IS programs.

Sub-step1: calculate the distances between each of the IS programs on each attribute. This initial calculation, using expression (15), will result in eleven $15 \times 15$ distance matrices.

For example, for the configuration design range attribute distance between IS program 01 and IS program 02 is simply

$\Delta\left(\right.$ IS program 01, IS program 02) $=0.25 \sqrt{\left(\underline{x}_{01 \text { rang }}-\underline{x}_{02 \text { rang }}\right)^{2}}+0.5 \sqrt{\left(\tilde{x}_{01 \text { rang }}-\tilde{x}_{02 \text { rang }}\right)^{2}}+$ $0.25 \sqrt{\left(\bar{x}_{01 \text { rang }}-\bar{x}_{02 \text { rang }}\right)^{2}}=0.361$.

The matrix with the distance scores is shown in Table 5.

Sub-step2: determine the neighborhood relation. For each attribute a relational matrix is determined. For the illustrative example a neighborhood threshold (size) $\delta=0.12$ is assumed. The neighborhood relational matrix is defined as:

$$
M(N)=\left(r_{i j}\right)_{n \times n}, \text { where } r_{i j}=\left\{\begin{array}{cc}
1, & \Delta\left(x_{i}, x_{j}\right) \leq \delta, \\
0, & \text { otherwise. }
\end{array}\right.
$$

For the elements $r_{12}=r_{21}=0$ of this matrix because $\Delta\left(x_{1}, x_{2}\right)=0.36>0.12$. $M(15)=\left(r_{i j}\right)_{15 \times 15}$ is shown in Table 6 . The diagonal matrix elements are set to 1 . That is $r_{\mathrm{ii}}=$ 1 because $\Delta^{B}\left(x_{i}, x_{i}\right)=0 \leq \delta$. 


\begin{tabular}{|c|c|c|c|c|c|c|c|c|c|c|c|c|c|c|c|c|c|c|c|}
\hline \multirow{4}{*}{ 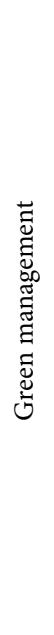 } & 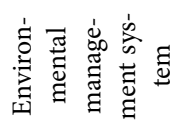 & $\begin{array}{l}\hat{\sigma} \\
0 \\
\hat{0} \\
\hat{e}\end{array}$ & $\begin{array}{l}\hat{\kappa} \\
0 \\
i n \\
0 \\
0 \\
\tilde{n} \\
e\end{array}$ & 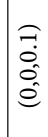 & $\begin{array}{l}\hat{=} \\
\hat{a} \\
\hat{e}\end{array}$ & $\begin{array}{l}\tilde{n} \\
0 \\
-1 \\
0 \\
0\end{array}$ & & 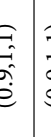 & $\begin{array}{l}\overrightarrow{\hat{a}} \\
\overrightarrow{\hat{e}}\end{array}$ & $\begin{array}{l}0 \\
0 \\
0 \\
0 \\
0\end{array}$ & $\begin{array}{l}\hat{a} \\
\hat{a} \\
\hat{0} \\
\hat{e}\end{array}$ & $\begin{array}{l}\widehat{T} \\
0 \\
0 \\
0 \\
\hat{e}\end{array}$ & $\begin{array}{l}\hat{0} \\
0 \\
0 \\
0 \\
0\end{array}$ & $\begin{array}{l}\hat{a} \\
\hat{0} \\
\hat{a} \\
\hat{e}\end{array}$ & $\begin{array}{l}\hat{E} \\
0 \\
0 \\
\hat{n} \\
0 \\
\hat{n} \\
e \\
e\end{array}$ & $\begin{array}{c}\hat{\theta} \\
\hat{a} \\
\hat{e}\end{array}$ & $\begin{array}{l}0 \\
0 \\
0 \\
0 \\
0 \\
0\end{array}$ & $\begin{array}{l}0 \\
0 \\
0 \\
0 \\
0\end{array}$ & $\begin{array}{l}\approx \\
= \\
=\end{array}$ \\
\hline & 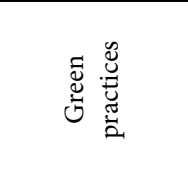 & $\begin{array}{l}\text { Î } \\
\hat{N} \\
0 \\
10 \\
10 \\
0 \\
0 \\
0 \\
0\end{array}$ & $\begin{array}{l}0 \\
0 \\
0 \\
0 \\
0 \\
0 \\
0 \\
+1 \\
0 \\
0 \\
0\end{array}$ & $\begin{array}{l}1 \\
10 \\
10 \\
0 \\
0 \\
0 \\
0 \\
0 \\
0 \\
0 \\
0 \\
0\end{array}$ & $\begin{array}{l}\mathbb{1} \\
\hat{N} \\
0 \\
0 \\
0 \\
0 \\
0 \\
0 \\
0 \\
0\end{array}$ & 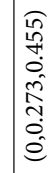 & 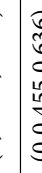 & 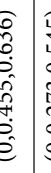 & 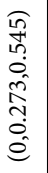 & $\begin{array}{c}\text { I } \\
\hat{N} \\
0 \\
+0 \\
0 \\
0 \\
0 \\
e \\
e \\
0\end{array}$ & $\begin{array}{l}\infty \\
\infty \\
\infty \\
0 \\
0 \\
0 \\
0 \\
0 \\
0 \\
0 \\
0\end{array}$ & 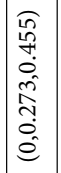 & $\begin{array}{l}= \\
\hat{0} \\
\hat{0} \\
0 \\
0 \\
0\end{array}$ & $\begin{array}{l}\mathbb{1} \\
\hat{N} \\
0 \\
0 \\
01 \\
0 \\
0 \\
0 \\
0 \\
0\end{array}$ & $\begin{array}{l}0 \\
0 \\
0 \\
0 \\
0 \\
0 \\
10 \\
10 \\
0 \\
0 \\
0 \\
0\end{array}$ & 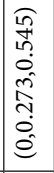 & $\begin{array}{l}\text { I } \\
\hat{N} \\
0 \\
\hat{0} \\
0 \\
0 \\
0 \\
0\end{array}$ & $\begin{array}{l}0 \\
0 \\
0 \\
0\end{array}$ & 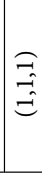 \\
\hline & 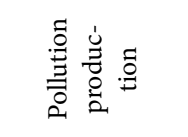 & $\begin{array}{l}\hat{\sigma} \\
\hat{a} \\
\hat{0} \\
e\end{array}$ & $\begin{array}{l}\hat{\kappa} \\
0 \\
\hat{n} \\
0 \\
\hat{n} \\
e \\
e\end{array}$ & $\begin{array}{l}\text { न. } \\
0 \\
0 \\
0\end{array}$ & $\overrightarrow{\hat{\theta}}$ & $\begin{array}{l}\hat{n} \\
\vdots \\
-\hat{0} \\
0 \\
\hat{e}\end{array}$ & & $\begin{array}{ll}E \\
e \\
e\end{array}$ & $\begin{array}{l}\widehat{c} \\
0 \\
0 \\
0 \\
0\end{array}$ & $\begin{array}{l}\hat{a} \\
\hat{a} \\
0 \\
\hat{N} \\
e\end{array}$ & $\begin{array}{l}\hat{\hat{0}} \\
0 \\
\hat{n} \\
0 \\
\tilde{n} \\
\hat{e}\end{array}$ & $\begin{array}{l}\hat{\hat{\theta}} \\
\hat{\sigma} \\
\hat{e}\end{array}$ & 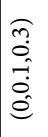 & 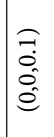 & $\begin{array}{l}1 \\
0 \\
0 \\
0 \\
0 \\
0\end{array}$ & $\begin{array}{l}\hat{E} \\
\hat{0} \\
\hat{n} \\
0 \\
\tilde{n} \\
e \\
e\end{array}$ & $\begin{array}{l}\sigma \\
0 \\
\hat{0} \\
0 \\
i n \\
e\end{array}$ & $\begin{array}{l}0 \\
0 \\
0 \\
0 \\
0\end{array}$ & $\begin{array}{l}= \\
=\end{array}$ \\
\hline & 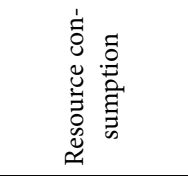 & 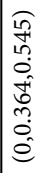 & $\begin{array}{l}\text { Ĉ} \\
0 \\
0 \\
0 \\
0 \\
0\end{array}$ & 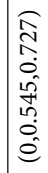 & 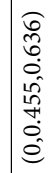 & 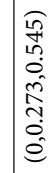 & & 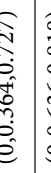 & 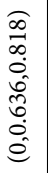 & 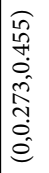 & 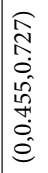 & $\begin{array}{c}\widehat{F} \\
\hat{0} \\
\tilde{n} \\
0 \\
\hat{n} \\
\hat{N} \\
0 \\
0 \\
0\end{array}$ & $\begin{array}{l}0 \\
\infty \\
\infty \\
0 \\
0 \\
0 \\
0 \\
+1 \\
0 \\
0 \\
0 \\
0\end{array}$ & $\begin{array}{l}\text { से } \\
0 \\
0 \\
0 \\
0 \\
0 \\
0 \\
0 \\
0\end{array}$ & 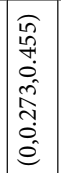 & $\begin{array}{c}0 \\
\infty \\
\infty \\
0 \\
0 \\
10 \\
10 \\
0 \\
0 \\
0 \\
0\end{array}$ & 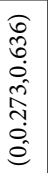 & $\begin{array}{l}0 \\
0 \\
0 \\
\hat{\theta}\end{array}$ & $\begin{array}{l}= \\
= \\
=\end{array}$ \\
\hline \multirow{5}{*}{ 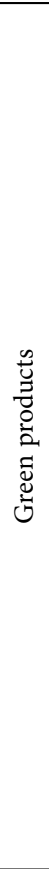 } & 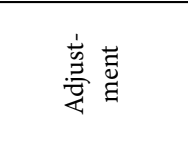 & $\begin{array}{l}\hat{\vec{b}} \\
\hat{e}\end{array}$ & $\begin{array}{c}\hat{n} \\
0 \\
-1 \\
0 \\
0 \\
0\end{array}$ & $\begin{array}{l}\text { C. } \\
0 \\
0 \\
0\end{array}$ & $\begin{array}{l}\hat{\sigma} \\
\hat{D} \\
\hat{i} \\
\hat{e}\end{array}$ & $\begin{array}{c}\hat{R} \\
0 \\
i n \\
0 \\
0 \\
\tilde{n} \\
e\end{array}$ & & $\begin{array}{l}E \\
\hat{e}\end{array}$ & $\begin{array}{l}0 \\
\tilde{m} \\
0 \\
0 \\
0 \\
0 \\
0\end{array}$ & $\begin{array}{l}\hat{\vec{b}} \\
\hat{e}\end{array}$ & $\begin{array}{l}\text { Ê. } \\
0 \\
i n \\
0 \\
\tilde{n} \\
e \\
e\end{array}$ & 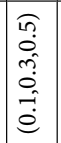 & $\begin{array}{l}\hat{a} \\
\hat{\sigma} \\
\hat{0} \\
\hat{e}\end{array}$ & $\begin{array}{l}\text { Ta } \\
0 \\
\hat{n} \\
0 \\
\hat{n} \\
e \\
e\end{array}$ & $\begin{array}{l}1 \\
0 \\
0 \\
0 \\
0 \\
0\end{array}$ & 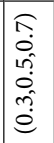 & $\begin{array}{l}\hat{a} \\
0 \\
\hat{0} \\
0 \\
i n \\
e \\
0\end{array}$ & $\begin{array}{l}0 \\
0 \\
0 \\
0 \\
0\end{array}$ & $\begin{array}{l}= \\
= \\
=\end{array}$ \\
\hline & 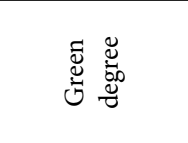 & $\begin{array}{l}\hat{\vec{a}} \\
\hat{e}\end{array}$ & 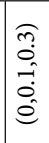 & $\begin{array}{l}\text { न. } \\
0 \\
0 \\
0\end{array}$ & $\begin{array}{l}\text { Oे } \\
0 \\
0 \\
0 \\
0\end{array}$ & $\begin{array}{l}\hat{a} \\
0 \\
\hat{0} \\
\hat{e}\end{array}$ & & 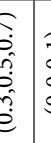 & $\begin{array}{l}0 \\
0 \\
0 \\
0 \\
0 \\
0\end{array}$ & $\begin{array}{l}\hat{\vec{a}} \\
\hat{a} \\
\hat{e}\end{array}$ & $\begin{array}{c}\hat{n} \\
0 \\
\hat{0} \\
0 \\
\hat{e} \\
\hat{e}\end{array}$ & $\begin{array}{l}\overrightarrow{\hat{\theta}} \\
\hat{\hat{e}}\end{array}$ & $\begin{array}{l}\hat{\vec{a}} \\
\hat{a}\end{array}$ & $\begin{array}{l}\hat{0} \\
0 \\
0 \\
0\end{array}$ & $\begin{array}{l}\hat{\sigma} \\
\hat{\sigma} \\
\hat{\delta} \\
\hat{e}\end{array}$ & $\mid \begin{array}{c}\hat{E} \\
\hat{i} \\
i n \\
0 \\
0 \\
e \\
e \\
0\end{array}$ & $\begin{array}{l}0 \\
0 \\
0 \\
0 \\
0\end{array}$ & $\begin{array}{l}0 \\
0 \\
0 \\
0 \\
0\end{array}$ & $\begin{array}{l}= \\
= \\
=\end{array}$ \\
\hline & 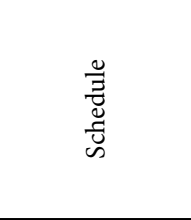 & 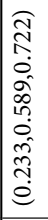 & 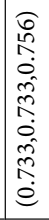 & 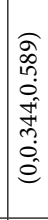 & 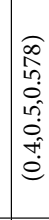 & 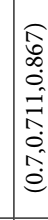 & & 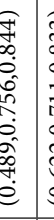 & 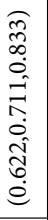 & 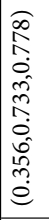 & 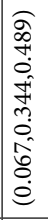 & $\begin{array}{l}0 \\
0 \\
h \\
0 \\
0 \\
\hat{N} \\
0 \\
0 \\
0 \\
0 \\
0 \\
0 \\
0\end{array}$ & 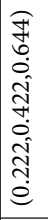 & 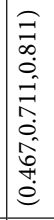 & 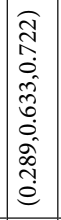 & 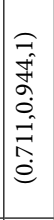 & 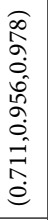 & $\begin{array}{l}0 \\
0 \\
0 \\
\hat{e}\end{array}$ & $\begin{array}{l}= \\
= \\
=\end{array}$ \\
\hline & 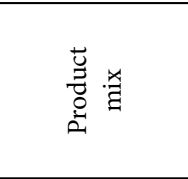 & $\begin{array}{l}0 \\
0 \\
0 \\
0 \\
0 \\
0 \\
\hat{1} \\
0 \\
0 \\
0 \\
0\end{array}$ & $\begin{array}{l}1 \\
\hat{n} \\
0 \\
0 \\
0 \\
0 \\
0 \\
0 \\
0 \\
0\end{array}$ & 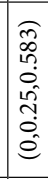 & $\begin{array}{l}10 \\
10 \\
0 \\
10 \\
n \\
0 \\
0 \\
0\end{array}$ & 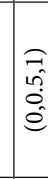 & & $\begin{array}{l}\text { Ê } \\
0 \\
0 \\
0 \\
0 \\
0 \\
0 \\
e \\
e\end{array}$ & $\begin{array}{l}\widehat{0} \\
0 \\
0 \\
0 \\
0 \\
\hat{\vdots} \\
\dot{0} \\
0 \\
0 \\
0\end{array}$ & $\begin{array}{l}0 \\
0 \\
0 \\
\infty \\
m \\
0 \\
0 \\
0 \\
0\end{array}$ & $\begin{array}{l}\text { Ê } \\
0 \\
0 \\
0 \\
0 \\
0 \\
0 \\
0 \\
0 \\
0 \\
0\end{array}$ & 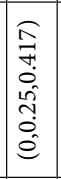 & $\begin{array}{l}\mathbb{1} \\
0 \\
0 \\
0 \\
0 n \\
0 \\
0 \\
0 \\
0\end{array}$ & 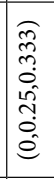 & $\mid \begin{array}{l}n \\
n \\
0 \\
0 \\
n \\
0 \\
0 \\
0 \\
0\end{array}$ & $\begin{array}{l}1 \\
\hat{n} \\
0 \\
0 \\
\infty \\
0 \\
0 \\
0 \\
0 \\
0\end{array}$ & $\begin{array}{l}\text { E } \\
\exists \\
0 \\
0 \\
\hat{0} \\
0 \\
0 \\
0 \\
0\end{array}$ & $\begin{array}{l}0 \\
0 \\
0 \\
0\end{array}$ & $\begin{array}{l}\approx \\
= \\
=\end{array}$ \\
\hline & 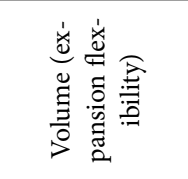 & 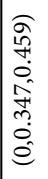 & $\begin{array}{l}0 \\
0 \\
0 \\
0 \\
0 \\
\hat{1} \\
i n \\
0 \\
0 \\
0\end{array}$ & 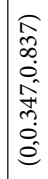 & 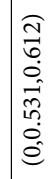 & 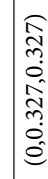 & & $\begin{array}{l}0 \\
0 \\
0 \\
0 \\
0 \\
1 \\
0 \\
0 \\
0 \\
e \\
0\end{array}$ & 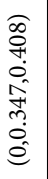 & 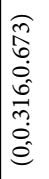 & $\begin{array}{l}\text { हे } \\
\hat{n} \\
\dot{0} \\
\dot{0} \\
0\end{array}$ & 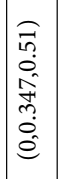 & $\begin{array}{l}0 \\
0 \\
2 \\
0 \\
\hat{1} \\
0 \\
0 \\
0 \\
0 \\
0\end{array}$ & $\begin{array}{l}\text { in } \\
\hat{n} \\
0 \\
0 \\
0 \\
0 \\
0 \\
0 \\
0 \\
0\end{array}$ & $\begin{array}{l}0 \\
2 \\
2 \\
0 \\
0 \\
0 \\
\vdots \\
0 \\
0 \\
0 \\
0\end{array}$ & 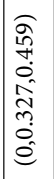 & 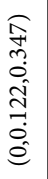 & $\begin{array}{l}0 \\
0 \\
0 \\
0\end{array}$ & $\begin{array}{l}\approx \\
= \\
=\end{array}$ \\
\hline \multirow{2}{*}{ 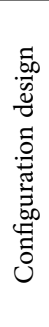 } & 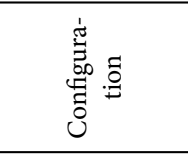 & $\begin{array}{l}\hat{=} \\
\hat{a} \\
\hat{e}\end{array}$ & $\begin{array}{l}\hat{n} \\
0 \\
\hat{0} \\
0 \\
\hat{0}\end{array}$ & $\begin{array}{l}\hat{\hat{e}} \\
\hat{a}\end{array}$ & 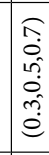 & $\begin{array}{c}\pi n \\
0 \\
n \\
0 \\
0 \\
\tilde{0} \\
0\end{array}$ & & $\begin{array}{l}0 \\
0 \\
0 \\
0 \\
0 \\
e \\
e \\
0\end{array}$ & $\begin{array}{l}\text { दे } \\
0 \\
0 \\
0 \\
0\end{array}$ & $\begin{array}{c}\hat{a} \\
\hat{\sigma} \\
\hat{0} \\
\hat{0}\end{array}$ & $\begin{array}{l}\hat{E} \\
0 \\
\hat{n} \\
0 \\
\hat{n} \\
\hat{e}\end{array}$ & $\begin{array}{c}0 \\
0 \\
0 \\
0 \\
0 \\
0\end{array}$ & $\begin{array}{l}\hat{\Omega} \\
0 \\
i n \\
0 \\
0 \\
\tilde{n} \\
e \\
e\end{array}$ & $\begin{array}{l}\hat{\sigma} \\
\hat{0} \\
\hat{0} \\
i \hat{0} \\
e\end{array}$ & $\mid \begin{array}{c}\widehat{0} \\
0 \\
-\hat{0} \\
\hat{0} \\
\hat{e}\end{array}$ & $\begin{array}{l}\hat{a} \\
\hat{a} \\
\hat{0} \\
\hat{e}\end{array}$ & 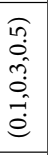 & $\begin{array}{l}0 \\
0 \\
\hat{0} \\
\hat{0}\end{array}$ & $\begin{array}{l}= \\
=\end{array}$ \\
\hline & 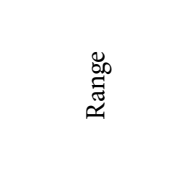 & \begin{tabular}{l} 
F \\
\multirow{H}{*}{} \\
0 \\
$\hat{N}$ \\
0 \\
0 \\
0 \\
0
\end{tabular} & $\begin{array}{l}2 \\
\hat{0} \\
\stackrel{0}{1} \\
\hat{0} \\
0 \\
0\end{array}$ & $\begin{array}{l}0 \\
0 \\
\hat{0} \\
0 \\
0 \\
0 \\
0 \\
0 \\
0 \\
0 \\
0\end{array}$ & $\begin{array}{l}\text { त̂ } \\
0 \\
0 \\
0 \\
\hat{\infty} \\
\hat{N} \\
0 \\
0 \\
0 \\
0\end{array}$ & 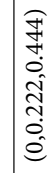 & & $\begin{array}{l}0 \\
0 \\
0 \\
0 \\
0 \\
0 \\
0 \\
0 \\
0 \\
0 \\
0\end{array}$ & 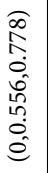 & 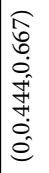 & $\begin{array}{l}\widehat{\sigma} \\
\infty \\
\infty \\
0 \\
0 \\
\infty \\
\hat{0} \\
0 \\
0 \\
0 \\
0\end{array}$ & $\begin{array}{l}0 \\
0 \\
0 \\
0 \\
0 \\
0 \\
\hat{N} \\
\hat{m} \\
0 \\
0 \\
0\end{array}$ & $\begin{array}{l}\text { Ê } \\
0 \\
0 \\
0 \\
\text { 亲 } \\
0 \\
0 \\
0 \\
0\end{array}$ & \begin{tabular}{l} 
F \\
\multirow{H}{0}{} \\
0 \\
$\hat{m}$ \\
0 \\
0 \\
0
\end{tabular} & $\begin{array}{l}2 \\
\hat{A} \\
0 \\
0 \\
0 \\
0 \\
0\end{array}$ & 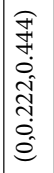 & $\begin{array}{l}\widehat{\approx} \\
\tilde{m} \\
0 \\
\hat{\Xi} \\
\exists \\
0 \\
0 \\
0\end{array}$ & $\begin{array}{l}0 \\
0 \\
0 \\
0\end{array}$ & $\begin{array}{l}\approx \\
= \\
=\end{array}$ \\
\hline \multicolumn{2}{|c|}{ 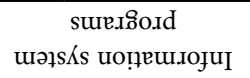 } & $\begin{array}{l}\overrightarrow{0} \\
\stackrel{9}{G}\end{array}$ & $\begin{array}{l}\text { 今े } \\
\text {. }\end{array}$ & 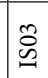 & 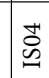 & 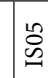 & & $\begin{array}{l}8 \\
0 \\
0\end{array}$ & 鸽 & 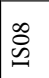 & 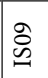 & 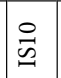 & $\vec{\Xi}$ & $\begin{array}{l}\tilde{a} \\
\stackrel{a}{a}\end{array}$ & $\begin{array}{l}m \\
\vec{n}\end{array}$ & 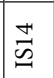 & $\begin{array}{l}\stackrel{n}{n} \\
\vec{n}\end{array}$ & 䚄 & 宏 \\
\hline
\end{tabular}


Table 5. The distance matrix for the configuration design range attribute between IS programs' normalized scores

\begin{tabular}{|l|l|l|l|l|l|l|l|l|l|l|l|l|l|l|l|l|}
\hline & IS01 & IS02 & IS03 & IS04 & IS05 & IS06 & IS07 & IS08 & IS09 & IS10 & IS11 & IS12 & IS13 & IS14 & IS15 \\
\hline IS01 & 0.000 & 0.361 & 0.194 & 0.056 & 0.056 & 0.278 & 0.194 & 0.111 & 0.333 & 0.028 & 0.111 & 0.000 & 0.306 & 0.056 & 0.139 \\
\hline IS02 & 0.361 & 0.000 & 0.167 & 0.306 & 0.417 & 0.083 & 0.167 & 0.250 & 0.028 & 0.333 & 0.250 & 0.361 & 0.056 & 0.417 & 0.500 \\
\hline IS03 & 0.194 & 0.167 & 0.000 & 0.139 & 0.250 & 0.083 & 0.000 & 0.083 & 0.139 & 0.167 & 0.083 & 0.194 & 0.111 & 0.250 & 0.333 \\
\hline IS04 & 0.056 & 0.306 & 0.139 & 0.000 & 0.111 & 0.222 & 0.139 & 0.056 & 0.278 & 0.028 & 0.056 & 0.056 & 0.250 & 0.111 & 0.194 \\
\hline IS05 & 0.056 & 0.417 & 0.250 & 0.111 & 0.000 & 0.333 & 0.250 & 0.167 & 0.389 & 0.083 & 0.167 & 0.056 & 0.361 & 0.000 & 0.083 \\
\hline IS06 & 0.278 & 0.083 & 0.083 & 0.222 & 0.333 & 0.000 & 0.083 & 0.167 & 0.056 & 0.250 & 0.167 & 0.278 & 0.028 & 0.333 & 0.417 \\
\hline IS07 & 0.194 & 0.167 & 0.000 & 0.139 & 0.250 & 0.083 & 0.000 & 0.083 & 0.139 & 0.167 & 0.083 & 0.194 & 0.111 & 0.250 & 0.333 \\
\hline IS08 & 0.111 & 0.250 & 0.083 & 0.056 & 0.167 & 0.167 & 0.083 & 0.000 & 0.222 & 0.083 & 0.000 & 0.111 & 0.194 & 0.167 & 0.250 \\
\hline IS09 & 0.333 & 0.028 & 0.139 & 0.278 & 0.389 & 0.056 & 0.139 & 0.222 & 0.000 & 0.306 & 0.222 & 0.333 & 0.083 & 0.389 & 0.472 \\
\hline IS10 & 0.028 & 0.333 & 0.167 & 0.028 & 0.083 & 0.250 & 0.167 & 0.083 & 0.306 & 0.000 & 0.083 & 0.028 & 0.278 & 0.083 & 0.167 \\
\hline IS11 & 0.111 & 0.250 & 0.083 & 0.056 & 0.167 & 0.167 & 0.083 & 0.000 & 0.222 & 0.083 & 0.000 & 0.111 & 0.194 & 0.167 & 0.250 \\
\hline IS12 & 0.000 & 0.361 & 0.194 & 0.056 & 0.056 & 0.278 & 0.194 & 0.111 & 0.333 & 0.028 & 0.111 & 0.000 & 0.306 & 0.056 & 0.139 \\
\hline IS13 & 0.306 & 0.056 & 0.111 & 0.250 & 0.361 & 0.028 & 0.111 & 0.194 & 0.083 & 0.278 & 0.194 & 0.306 & 0.000 & 0.361 & 0.444 \\
\hline IS14 & 0.056 & 0.417 & 0.250 & 0.111 & 0.000 & 0.333 & 0.250 & 0.167 & 0.389 & 0.083 & 0.167 & 0.056 & 0.361 & 0.000 & 0.083 \\
\hline IS15 & 0.139 & 0.500 & 0.333 & 0.194 & 0.083 & 0.417 & 0.333 & 0.250 & 0.472 & 0.167 & 0.250 & 0.139 & 0.444 & 0.083 & 0.000 \\
\hline
\end{tabular}

Table 6. The relational matrix for the configuration design range attribute between IS programs' normalized scores

\begin{tabular}{|l|c|c|c|c|c|c|c|c|c|c|c|c|c|c|c|c|}
\hline & IS01 & IS02 & IS03 & IS04 & IS05 & IS06 & IS07 & IS08 & IS09 & IS10 & IS11 & IS12 & IS13 & IS14 & IS15 & SUM \\
\hline IS01 & 1 & 0 & 0 & 1 & 1 & 0 & 0 & 1 & 0 & 1 & 1 & 1 & 0 & 1 & 0 & 8 \\
\hline IS02 & 0 & 1 & 0 & 0 & 0 & 1 & 0 & 0 & 1 & 0 & 0 & 0 & 1 & 0 & 0 & 4 \\
\hline IS03 & 0 & 0 & 1 & 0 & 0 & 1 & 1 & 1 & 0 & 0 & 1 & 0 & 1 & 0 & 0 & 6 \\
\hline IS04 & 1 & 0 & 0 & 1 & 1 & 0 & 0 & 1 & 0 & 1 & 1 & 1 & 0 & 1 & 0 & 8 \\
\hline IS05 & 1 & 0 & 0 & 1 & 1 & 0 & 0 & 0 & 0 & 1 & 0 & 1 & 0 & 1 & 1 & 7 \\
\hline IS06 & 0 & 1 & 1 & 0 & 0 & 1 & 1 & 0 & 1 & 0 & 0 & 0 & 1 & 0 & 0 & 6 \\
\hline IS07 & 0 & 0 & 1 & 0 & 0 & 1 & 1 & 1 & 0 & 0 & 1 & 0 & 1 & 0 & 0 & 6 \\
\hline IS08 & 1 & 0 & 1 & 1 & 0 & 0 & 1 & 1 & 0 & 1 & 1 & 1 & 0 & 0 & 0 & 8 \\
\hline IS09 & 0 & 1 & 0 & 0 & 0 & 1 & 0 & 0 & 1 & 0 & 0 & 0 & 1 & 0 & 0 & 4 \\
\hline IS10 & 1 & 0 & 0 & 1 & 1 & 0 & 0 & 1 & 0 & 1 & 1 & 1 & 0 & 1 & 0 & 8 \\
\hline IS11 & 1 & 0 & 1 & 1 & 0 & 0 & 1 & 1 & 0 & 1 & 1 & 1 & 0 & 0 & 0 & 8 \\
\hline IS12 & 1 & 0 & 0 & 1 & 1 & 0 & 0 & 1 & 0 & 1 & 1 & 1 & 0 & 1 & 0 & 8 \\
\hline IS13 & 0 & 1 & 1 & 0 & 0 & 1 & 1 & 0 & 1 & 0 & 0 & 0 & 1 & 0 & 0 & 6 \\
\hline IS14 & 1 & 0 & 0 & 1 & 1 & 0 & 0 & 0 & 0 & 1 & 0 & 1 & 0 & 1 & 1 & 7 \\
\hline IS15 & 0 & 0 & 0 & 0 & 1 & 0 & 0 & 0 & 0 & 0 & 0 & 0 & 0 & 1 & 1 & 3 \\
\hline
\end{tabular}

\section{Step 4: Calculate attribute information content}

The neighborhood RST is used to determine the information content for each attribute om this step. First, determine the information content for the attributes $(c)$ using expression (19) (Liang, Shi, Li, \& Wierman, 2006):

$$
\mathrm{I}(c)=1-\frac{1}{|U|^{2}} \sum_{i=1}^{|U|}\left|X_{i}^{c}\right| \text {. }
$$


$\mathrm{I}(c)$ is the information content which measures the ability of the classification for this attribute. If an attribute has more information content, it will be more important in this system. $|U|$ is the number of IS programs. $\left|X_{i}^{c}\right|$ is defined as the number of members within the attribute $c$ for IS program $i$. In other words, it is the neighborhood information granule of IS programs with similar attributes values across the attribute $c$ of IS program $i$.

Illustratively, the information granule for the configuration design range attribute and the evaluation of $\left|X_{01}^{\text {rang }}\right|$ (i.e. $\delta_{\text {rang }}$ (IS program 01)) is also sought. The rows of $M_{\text {rang }}(15)$ are summed from first to last column in Table 6 . Thus $\left|X_{01}^{\text {rang }}\right|=\delta_{\text {rang }}$ (IS program 01$)=8$.

The various neighborhood information granules $\left(X_{i}^{c}\right)$ for the IS program set are determined when they have similar attributes values across an attribute $c$ for an IS program $i$. The information content for the configuration design range attribute is calculated using expression (19): $\mathrm{I}(\mathrm{rang})=1-\left(\frac{1}{|15|^{2}}(8+4+\ldots+3)\right)=1-\frac{97}{225}=0.569$.

Table 7 contains the information content results. The information content helps determine the green flexibility attribute importance weights in the next step.

Table 7. Information content and weight for each green flexibility attribute

\begin{tabular}{|l|l|c|c|}
\hline \multicolumn{1}{|c|}{ Categories } & \multicolumn{1}{|c|}{ Green flexibility attributes } & Information content & Weights \\
\hline \multirow{4}{*}{ Configuration design } & Range & 0.569 & 0.087 \\
\cline { 2 - 4 } & Configuration & 0.756 & 0.116 \\
\hline \multirow{5}{*}{ Green products } & Volume (expansion flexibility) & 0.533 & 0.082 \\
\cline { 2 - 4 } & Product mix & 0.524 & 0.080 \\
\cline { 2 - 4 } & Schedule & 0.658 & 0.101 \\
\cline { 2 - 4 } & Green degree & 0.604 & 0.093 \\
\cline { 2 - 4 } & Adaptability & 0.738 & 0.113 \\
\hline \multirow{5}{*}{ Green management } & Resource consumption & 0.462 & 0.071 \\
\cline { 2 - 4 } & Pollution production & 0.684 & 0.105 \\
\cline { 2 - 4 } & Green practices & 0.382 & 0.059 \\
\cline { 2 - 4 } & Environmental management system & 0.604 & 0.093 \\
\hline
\end{tabular}

\section{Step 5: Determine each attribute weight}

Expression (20) is used to identify the information weight of each green flexibility attribute.

$$
w\left(c_{j}\right)=\frac{\mathrm{I}\left(c_{j}\right)}{\sum_{j=1}^{m} \mathrm{I}\left(c_{j}\right)} .
$$

Where aggregated weights sum to one, or $\sum_{j=1}^{n} w_{j}=1$. 
The cumulative information content across attributes is $\sum_{j=1}^{m} \mathrm{I}\left(c_{j}\right)=6.52$. The information content for the configuration design range attribute is 0.569 , and the normalized weight is $w($ rang $)=\frac{0.569}{6.52}=0.087$. All attribute weights are shown in Table 7 .

Step 6: Determine the ideal and negative-ideal IS program

The maximum value from amongst each of the attributes, expression (21), are used to determine the 'ideal' reference IS program $I S^{+}$.

$$
I S^{+}=\left\{\otimes x_{1}^{+}, \ldots, \otimes x_{m}^{+}\right\}=\left\{\left(\max _{i} \bar{x}_{i k}, \max _{i} \bar{x}_{i k}, \max _{i} \bar{x}_{i k}\right)\right\} .
$$

Thus, $I S^{+}=\{(1,1,1),(1,1,1),(1,1,1),(1,1,1),(1,1,1),(1,1,1),(1,1,1),(1,1,1),(1,1,1),(1,1,1)$, $(1,1,1)\}$.

The nadir IS program, $I S^{-}$, is determined using expression (22) which uses the minimum value for each of the attributes,

$$
I S^{-}=\left\{x_{1}^{-}, \ldots, x_{m}^{-}\right\}=\left\{\left(\min _{i} \underline{x}_{i k}, \min _{i} \underline{x}_{i k}, \min _{i} \underline{x}_{i k}\right)\right\} .
$$

Thus, $I S^{-}=\{(0,0,0),(0,0,0),(0,0,0),(0,0,0),(0,0,0),(0,0,0),(0,0,0),(0,0,0),(0,0,0),(0,0,0)$, $(0,0,0)\}$. The $I S^{+}$and $I S^{-}$attribute values are summarized in Table 6.

\section{Step 7: Separation measures calculations}

The difference between the ideal and nadir reference IS program and each of the respective comparative IS programs is determined separately using expressions (23) and (24):

$$
\begin{aligned}
\otimes \mu_{i}^{+}= & \sqrt{\sum_{k=1}^{m}\left(w_{k}\left(\otimes x_{i k}-\otimes x_{k}^{+}\right)\right)^{2}}= \\
& \sqrt{\sum_{k=1}^{m}\left(w_{k}^{2} * \min \left(\left(\underline{x}_{i k}-\underline{x}_{k}^{+}\right)^{2},\left(\bar{x}_{i k}-\bar{x}_{k}^{+}\right)^{2}\right),\left(\tilde{x}_{i k}-\tilde{x}_{k}^{+}\right)^{2}, \max \left(\left(\underline{x}_{i k}-\underline{x}_{k}^{+}\right)^{2},\left(\bar{x}_{i k}-\bar{x}_{k}^{+}\right)^{2}\right)\right)} ; \\
\otimes \mu_{i}^{-}= & \sqrt{\sum_{k=1}^{m}\left(w_{k}\left(\otimes x_{i k}-\otimes x_{k}^{-}\right)\right)^{2}}= \\
& \sqrt{\sum_{k=1}^{m}\left(w_{k}^{2} * \min \left(\left(\underline{x}_{i k}-\underline{x}_{k}^{-}\right)^{2},\left(\bar{x}_{i k}-\bar{x}_{k}^{-}\right)^{2}\right),\left(\tilde{x}_{i k}-\tilde{x}_{k}^{-}\right)^{2}, \max \left(\left(\underline{x}_{i k}-\underline{x}_{k}^{-}\right)^{2},\left(\bar{x}_{i k}-\bar{x}_{k}^{-}\right)^{2}\right)\right)} .
\end{aligned}
$$

The separations $\otimes \mu_{i}^{+}$and $\otimes \mu_{i}^{-}$of each IS program are shown in Table 8 . 
Table 8. The relative closeness and separation measures for each IS program

\begin{tabular}{|c|c|c|c|}
\hline Information system programs & $\otimes \mu_{i}^{+}$ & $\otimes \mu_{i}^{-}$ & $\otimes T_{i}$ \\
\hline IS01 & $(0.087,0.115,0.193)$ & $(0.196,0.242,0.261)$ & $(0.431,0.679,0.924)$ \\
\hline IS02 & $(0.144,0.196,0.273)$ & $(0.085,0.15,0.2)$ & $(0.18,0.434,0.871)$ \\
\hline IS03 & $(0.194,0.236,0.284)$ & $(0.104,0.142,0.181)$ & $(0.225,0.375,0.604)$ \\
\hline IS04 & $(0.12,0.158,0.222)$ & $(0.158,0.204,0.232)$ & $(0.348,0.563,0.835)$ \\
\hline IS05 & $(0.148,0.201,0.26)$ & $(0.102,0.142,0.196)$ & $(0.224,0.413,0.786)$ \\
\hline IS06 & $(0.097,0.143,0.223)$ & $(0.172,0.221,0.252)$ & $(0.361,0.607,0.939)$ \\
\hline IS07 & $(0.195,0.231,0.277)$ & $(0.104,0.143,0.172)$ & $(0.233,0.382,0.573)$ \\
\hline IS08 & $(0.111,0.148,0.211)$ & $(0.175,0.225,0.251)$ & $(0.379,0.602,0.877)$ \\
\hline IS09 & $(0.107,0.158,0.257)$ & $(0.087,0.173,0.225)$ & $(0.181,0.523,1.156)$ \\
\hline IS10 & $(0.173,0.209,0.251)$ & $(0.143,0.17,0.188)$ & $(0.325,0.449,0.596)$ \\
\hline IS11 & $(0.13,0.177,0.251)$ & $(0.122,0.18,0.225)$ & $(0.257,0.504,0.892)$ \\
\hline IS12 & $(0.163,0.198,0.249)$ & $(0.105,0.158,0.199)$ & $(0.234,0.444,0.743)$ \\
\hline IS13 & $(0.174,0.216,0.277)$ & $(0.076,0.144,0.194)$ & $(0.162,0.401,0.775)$ \\
\hline IS14 & $(0.108,0.156,0.218)$ & $(0.147,0.199,0.236)$ & $(0.324,0.561,0.925)$ \\
\hline IS15 & $(0.164,0.214,0.253)$ & $(0.106,0.153,0.198)$ & $(0.235,0.417,0.733)$ \\
\hline
\end{tabular}

\section{Step 8: Ideal solution relative closeness calculation}

Using expression (25), the relative closeness $\otimes T_{i}$ for an alternative $I S_{i}$ with respect to $I S^{+}$ is calculated.

$$
\begin{aligned}
\otimes T_{i}= & \frac{\otimes \mu_{i}^{-}}{\otimes \mu_{i}^{+}+\otimes \mu_{i}^{-}}=\frac{\left(\underline{\mu}_{i}^{-}, \tilde{\mu}_{i}^{-}, \bar{\mu}_{i}^{-}\right)}{\left(\underline{\mu}_{i}^{+}+\underline{\mu}_{i}^{-}, \tilde{\mu}_{i}^{+}+\tilde{\mu}_{i}^{-}, \bar{\mu}_{i}^{+}+\bar{\mu}_{i}^{-}\right)}= \\
& \left(\operatorname { m i n } \left(\underline{\mu}_{i}^{-} /\left(\underline{\mu}_{i}^{+}+\underline{\mu}_{i}^{-}\right)^{\prime} /\left(\underline{\mu}_{i}^{-}+\underline{\mu}_{i}^{-}\right)^{,} \underline{\mu}_{i}^{-} /\left(\bar{\mu}_{i}^{+}+\bar{\mu}_{i}^{-}\right)^{,} \bar{\mu}_{i}^{-} /\left(\bar{\mu}_{i}^{+}+\bar{\mu}_{i}^{-}\right)\right.\right. \\
& , \tilde{\mu}_{i}^{-} /\left(\tilde{\mu}_{i}^{+}+\tilde{\mu}_{i}^{-}\right), \max \left(\underline{\mu}_{i}^{-} /\left(\underline{\mu}_{i}^{+}+\underline{\mu}_{i}^{-}\right)^{\prime} /\left(\underline{\mu}_{i}^{+}+\underline{\mu}_{i}^{-}\right)^{,} \underline{\mu}_{i}^{-} /\left(\bar{\mu}_{i}^{+}+\bar{\mu}_{i}^{-}\right)^{,} \bar{\mu}_{i}^{-} /\left(\bar{\mu}_{i}^{+}+\bar{\mu}_{i}^{-}\right),\right.
\end{aligned}
$$

The separations, $\otimes T_{i}$, of each alternative from the ideal solution are shown in Table 8 . Since the scores of the relative closeness values are in the form of TpGNs, the decision maker cannot directly judge which is better. To overcome this limitation dominance probability, a new approach, is introduced to provide some evaluation results, allowing for some variations in preference.

\section{Step 9: IS programs dominance probability calculations}

Although TOPSIS can deterministically rank IS programs these valuations, with intangible values and uncertain quantitative valuations, make a deterministic ranking suspect. Thus, this paper extends the TOPSIS evaluation using dominance probability values for each IS program when compared to other IS programs contribution to green flexibility in supply chains. 
The dominance probability degree is uses a dominance matrix. Expression (26) is used to develop a dominance probability matrix:

$$
P_{n \times n}=p\left(x_{i} \geq x_{j}\right)_{n \times n}, i, j=1, \ldots n .
$$

As an example, from Step 8, the relative closeness level of IS program 01 is $\otimes T_{01}=(0.431$, $0.679,0.924)$. The relative closeness level of IS program 04 is $(0.348,0.563,0.835)$. Then the probability is $p\left(I S_{01} \succ I S_{04}\right)=\frac{0.679-0.563+0.924-0.348}{0.493+0.487}=70.7 \%$, and measure that IS program 01 is better than IS program 04 . The integral dominance matrix result is show in Table 9.

Table 9. The dominance probability matrix

\begin{tabular}{|c|c|c|c|c|c|c|c|c|c|c|c|c|c|c|c|}
\hline & IS01 & IS02 & IS03 & IS04 & IS05 & IS06 & IS07 & IS08 & IS09 & IS10 & IS11 & IS12 & IS13 & IS14 & IS15 \\
\hline IS01 & $50.0 \%$ & $83.6 \%$ & $100.0 \%$ & $70.7 \%$ & $91.6 \%$ & $59.3 \%$ & $100.0 \%$ & $62.8 \%$ & $61.3 \%$ & $100.0 \%$ & $74.7 \%$ & $92.4 \%$ & $94.0 \%$ & $65.7 \%$ & $96.0 \%$ \\
\hline IS02 & $16.4 \%$ & $50.0 \%$ & $65.8 \%$ & $33.5 \%$ & $53.3 \%$ & $26.5 \%$ & $66.9 \%$ & $27.2 \%$ & $36.1 \%$ & $55.2 \%$ & $41.0 \%$ & $52.3 \%$ & $56.9 \%$ & $32.5 \%$ & $54.9 \%$ \\
\hline IS03 & $0.0 \%$ & $34.2 \%$ & $50.0 \%$ & $8.0 \%$ & $36.3 \%$ & $1.2 \%$ & $50.6 \%$ & $0.0 \%$ & $20.4 \%$ & $31.7 \%$ & $21.6 \%$ & $34.0 \%$ & $41.9 \%$ & $9.6 \%$ & $37.3 \%$ \\
\hline IS04 & $29.3 \%$ & $66.5 \%$ & $92.0 \%$ & $50.0 \%$ & $72.5 \%$ & $40.3 \%$ & $94.6 \%$ & $42.3 \%$ & $47.4 \%$ & $82.3 \%$ & $56.7 \%$ & $72.3 \%$ & $75.8 \%$ & $47.1 \%$ & $75.6 \%$ \\
\hline IS05 & $8.4 \%$ & $46.7 \%$ & $63.7 \%$ & $27.5 \%$ & $50.0 \%$ & $20.3 \%$ & $64.8 \%$ & $20.6 \%$ & $32.2 \%$ & $51.1 \%$ & $36.6 \%$ & $48.7 \%$ & $54.1 \%$ & $27.0 \%$ & $51.6 \%$ \\
\hline IS06 & $40.7 \%$ & $73.5 \%$ & $98.8 \%$ & $59.7 \%$ & $79.7 \%$ & $50.0 \%$ & $100.0 \%$ & $52.5 \%$ & $54.3 \%$ & $91.0 \%$ & $64.7 \%$ & $79.9 \%$ & $82.5 \%$ & $56.1 \%$ & $83.1 \%$ \\
\hline IS07 & $0.0 \%$ & $33.1 \%$ & $49.4 \%$ & $5.4 \%$ & $35.2 \%$ & $0.0 \%$ & $50.0 \%$ & $0.0 \%$ & $19.1 \%$ & $29.8 \%$ & $20.0 \%$ & $32.8 \%$ & $41.1 \%$ & $7.5 \%$ & $36.2 \%$ \\
\hline IS08 & $37.2 \%$ & $72.8 \%$ & $100.0 \%$ & $57.7 \%$ & $79.4 \%$ & $47.5 \%$ & $100.0 \%$ & $50.0 \%$ & $52.6 \%$ & $91.8 \%$ & $63.4 \%$ & $79.6 \%$ & $82.4 \%$ & $54.0 \%$ & $83.0 \%$ \\
\hline IS09 & $38.7 \%$ & $63.9 \%$ & $79.6 \%$ & $52.6 \%$ & $67.8 \%$ & $45.7 \%$ & $80.9 \%$ & $47.4 \%$ & $50.0 \%$ & $72.7 \%$ & $57.0 \%$ & $67.5 \%$ & $70.2 \%$ & $50.4 \%$ & $69.7 \%$ \\
\hline IS10 & $0.0 \%$ & $44.8 \%$ & $68.3 \%$ & $17.7 \%$ & $48.9 \%$ & $9.0 \%$ & $70.2 \%$ & $8.2 \%$ & $27.3 \%$ & $50.0 \%$ & $31.3 \%$ & $47.1 \%$ & $54.4 \%$ & $18.3 \%$ & $51.0 \%$ \\
\hline IS11 & $25.3 \%$ & $59.0 \%$ & $78.4 \%$ & $43.3 \%$ & $63.4 \%$ & $35.3 \%$ & $80.0 \%$ & $36.6 \%$ & $43.0 \%$ & $68.7 \%$ & $50.0 \%$ & $62.8 \%$ & $66.7 \%$ & $41.3 \%$ & $65.6 \%$ \\
\hline IS12 & $7.6 \%$ & $47.7 \%$ & $66.0 \%$ & $27.7 \%$ & $51.3 \%$ & $20.1 \%$ & $67.2 \%$ & $20.4 \%$ & $32.5 \%$ & $52.9 \%$ & $37.2 \%$ & $50.0 \%$ & $55.5 \%$ & $27.1 \%$ & $53.0 \%$ \\
\hline IS13 & $6.0 \%$ & $43.1 \%$ & $58.1 \%$ & $24.2 \%$ & $45.9 \%$ & $17.5 \%$ & $58.9 \%$ & $17.6 \%$ & $29.8 \%$ & $45.6 \%$ & $33.3 \%$ & $44.5 \%$ & $50.0 \%$ & $24.0 \%$ & $47.2 \%$ \\
\hline IS14 & $34.3 \%$ & $67.5 \%$ & $90.4 \%$ & $52.9 \%$ & $73.0 \%$ & $43.9 \%$ & $92.5 \%$ & $46.0 \%$ & $49.6 \%$ & $81.7 \%$ & $58.7 \%$ & $72.9 \%$ & $76.0 \%$ & $50.0 \%$ & $75.9 \%$ \\
\hline IS15 & $4.0 \%$ & $45.1 \%$ & $62.7 \%$ & $24.4 \%$ & $48.4 \%$ & $16.9 \%$ & $63.8 \%$ & $17.0 \%$ & $30.3 \%$ & $49.0 \%$ & $34.4 \%$ & $47.0 \%$ & $52.8 \%$ & $24.1 \%$ & $50.0 \%$ \\
\hline
\end{tabular}

The results in Table 9 show IS program 01 is the most preferred IS program to aid in green supply chain flexibility. IS program 01 has a $59.3 \%$ probability it better than IS program 06. The final ranks are:

$$
\begin{aligned}
& I S_{01} \succ I S_{06} \underset{52.3 \%}{\succ} I S_{08} \underset{52.6 \%}{\succ} I S_{09} \underset{50.4 \%}{\succ} I S_{14} \underset{52.9 \%}{\succ} I S_{04} \underset{56.7 \%}{\succ} I S_{11} \underset{59.0 \%}{\succ} \\
& I S_{02} \succ_{52.3 \%}^{\succ} I S_{12} \succ I S_{05.3 \%} \succ I S_{10} \succ_{51.1 \%}^{\succ} I S_{15} \underset{52.8 \%}{\succ} I S_{13} \underset{58.1 \%}{\succ} I S_{03} \underset{50.6 \%}{\succ} I S_{07} \text {, }
\end{aligned}
$$

where the expression " $I S_{01} \underset{59.3 \%}{\succ} I S_{06}$ " represents the $59.3 \%$ probability that IS program 01 is better than IS program 06 for aiding green supply chain flexibility based on the selected attributes and attribute valuations. It can also observed that for some situations the difference is so slight (e.g. IS programs 09 and 14) that the relative preference may not exist. 


\section{Sensitivity analysis}

To complete a sensitivity analysis the illustrative case, values of $\delta=0.12, \alpha=0.25$, and $\beta=0.5$ are altered.

\subsection{Varying parameter $\delta$}

The results for varying the parameter value of $\delta$ are shown in Figure 1. The IS program ranking results show some significant changes. For example, IS program 01 is the best IS program when $\delta=0.08,0.12,0.16,0.20$ and becomes the third best alternative when $\delta=0$ and 0.04 . Initial and sensitivity results show that the IS program 01 has higher TOPSIS values.

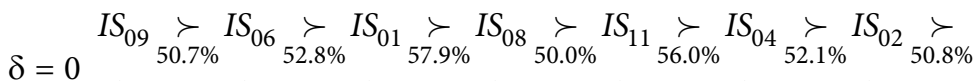

$$
\begin{aligned}
& \delta=0 \quad I S_{14} \underset{58.4 \%}{\succ} I S_{13} \underset{54.2 \%}{\succ} I S_{05} \underset{53.4 \%}{\succ} I S_{12} \underset{51.3 \%}{\succ} I S_{10} \underset{51.5 \%}{\succ} I S_{15} \underset{50.5 \%}{\succ} I S_{07} \underset{52.5 \%}{\succ} I S_{03} ;
\end{aligned}
$$

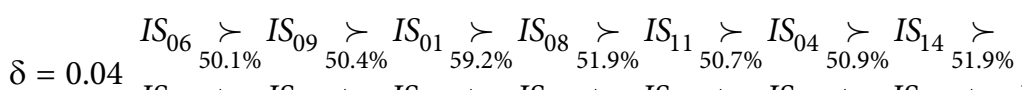

$$
\begin{aligned}
& \delta=0.04 I S_{02} \underset{57.5 \%}{\succ} I S_{13} \underset{52.9 \%}{\succ} I S_{05} \underset{51.1 \%}{\succ} I S_{12} \underset{52.1 \%}{\succ} I S_{10} \underset{51.8 \%}{\succ} I S_{15} \underset{52.1 \%}{\succ} I S_{07} \underset{53.0 \%}{\succ} I S_{03} ; \\
& \delta=0.08 S_{01} \succ I S_{06} \underset{53.5 \%}{\succ} I S_{09} \succ I S_{08} \underset{53.1 \%}{\succ} I S_{14} \underset{52.0 \%}{\succ} I S_{04} \underset{54.2 \%}{\succ} I S_{11} \succ \\
& \delta=0.08 I S_{02} \underset{56.1 \%}{\succ} I S_{13} \underset{50.2 \%}{\succ 3.4 \%} I S_{12} \underset{50.2 \%}{\succ} I S_{05} \underset{50.4 \%}{\succ} I S_{10} \underset{55.8 \%}{\succ} I S_{15} \underset{56.8 \%}{\succ} I S_{07} \underset{53.4 \%}{\succ} I S_{03} ; \\
& \delta=0.12 S_{01} \succ I S_{06} \succ S_{52.5 \%}^{\succ} I S_{08} \underset{52.3 \%}{\succ} I S_{09} \underset{50.4 \%}{\succ} I S_{14} \underset{53.0 \%}{\succ} I S_{04} \underset{56.7 \%}{\succ} I S_{11} \succ_{59.0 \%}^{\succ} \\
& \delta=0.12 I S_{02} \succ 2.3 \% \text { I } S_{12} \succ I S_{05} \succ I S_{10} \succ I S_{51.1 \%} \succ S_{52.8 \%}^{\succ} I S_{13} \underset{58.1 \%}{\succ} I S_{03} \underset{50.6 \%}{\succ} I S_{07} ; \\
& \delta=0.16 S_{01} \succ S_{68.3 \%} I S_{08} \succ I S_{06} \succ I S_{14} \underset{51.6 \%}{\succ} I S_{04} \underset{52.0 \%}{\succ} I S_{09} \underset{56.9 \%}{\succ} I S_{11} \succ \\
& I S_{12} \succ I S_{10} \underset{51.8 \%}{\succ} I S_{05} \underset{50.4 \%}{\succ} I S_{15} \underset{51.9 \%}{\succ} I S_{02} \underset{55.5 \%}{\succ} I S_{13} \underset{57.5 \%}{\succ} I S_{03} \underset{52.5 \%}{\succ} I S_{07} \text {; }
\end{aligned}
$$

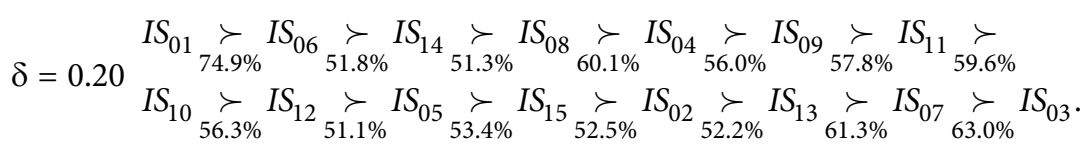

The dominance probability increases as $\delta$ becomes larger, which means it is more easy to distinguish between IS programs for improving green supply chain flexibility.

\subsection{Varying parameters $\alpha$ and $\beta$}

The distance measure for the TpGN was used to identify the information content of flexibility attributes in Step 3. $\beta$ is allowed to change over a range $0.5 \leq \beta \leq 1.0$, in increments of 0.1 with $\alpha=\frac{(1-\beta)}{2}$. The results from varying parameters $\alpha$ and $\beta$ are summarized in Figure 1 .

There are two interesting observations. First, some information content results are robust for varying parameters $\alpha$ and $\beta$, such as volume (expansion flexibility). This result indicates that the weight of $\alpha$ and $\beta$ will impact the attribute weight and relative closeness rank. Second, some information content results keep the same values for changes in $\alpha$ and $\beta$ values, such as adaptability. Those attributes are mainly qualitative data and which have similar scales assigned $\bar{x}$. 


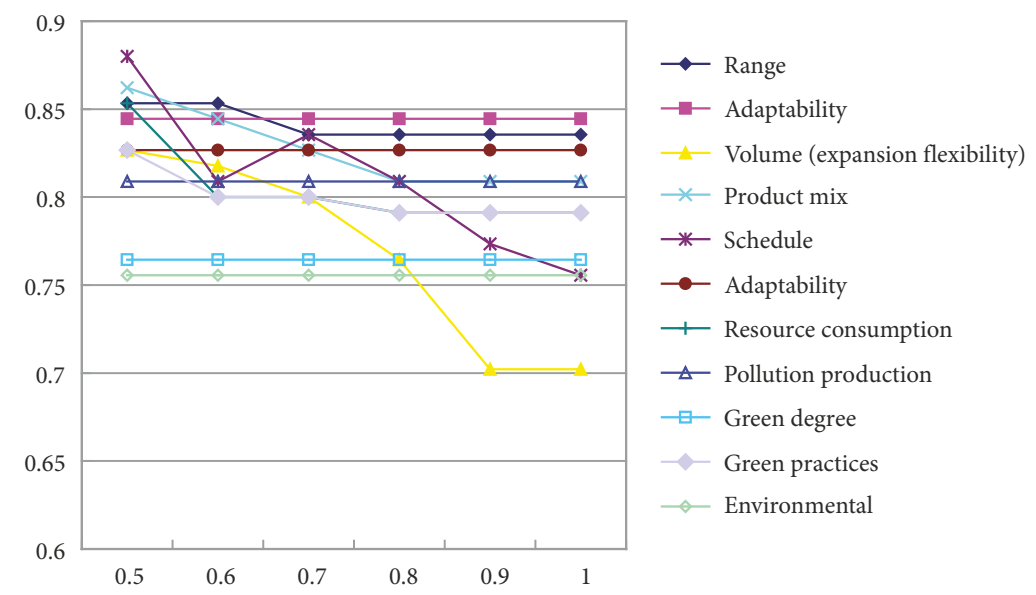

Figure 1. The information content of attributes for different values of $\beta$

\section{Conclusions}

Introduction of IS programs can aid in flexibilities for green supply chains. Many of these dimensions were identified in this paper. In order to effectively integrate these systems some form of evaluation and selection process must be completed. Yet, how to select the best IS program to achieve green flexible performance is not always clear and can become a complex exercise. To help reduce this complexity and the amount of data required, a methodology to help simplify and then realistically evaluate alternatives can be quite beneficial.

This study is one of the first effort to develop a categorization and methodology for green supply chain flexibility evaluation and integration into managerial decision making. This study has proposed a grey based neighborhood rough set and TOPSIS methodology to support such IS program evaluation and investment decisions to support green supply chain flexibility goals.

To address the complexity and broad data requirements necessary to make decisions in a green business environment, neighborhood rough set, TOPSIS and TpGNs are methodologically integrated into a nine-step investment evaluation and appraisal process. TpGNs allow for IS program evaluation in green supply chain flexibility and ambiguity from expert judgment, which adds to the evaluation complexity and data requirements. A challenge of many decision tools for supply chain flexibility management is how to deal with massive amounts of data, and how to leverage and apply accurate prediction and decision support analytics. This technique is especially positioned as an MCDM tool that can solve problems for big and complex data. For example, RST also can support large data sets of measures (Bai \& Sarkis, 2013a) by helping reduce attribute data according to information content. Three-parameter interval grey numbers can be used to evaluate incomplete and uncertain information, and can also effectively integrate flexibility features (range, volume, variety of data) and decision maker opinions. TOPSIS was extended to handle all kinds of data except TpGN.

In this data management and decision process, neighborhood rough set was used to define importance weights for the various green supply chain flexibility attributes. TOPSIS 
was used for ranking and identification of preferred IS program and computing results as probability terms. The innovation of this methodology is in extending neighborhood RST and TOPSIS to deal with the TpGN and provide a probability-based ranking result. The methodology was applied through an illustrative application.

This paper introduced a green supply chain flexibility measurements framework, which is a new contribution. The green supply chain flexibility matrix framework based on functional flexibilities and supply chain dimensions are used for IS program evaluation. A three dimensional framework of green supply chain flexibility is offered and includes configuration design, green products flexibility, and green management flexibility along four dimensions of supply chain activities, including supply, manufacturing, distribution/logistics, and reverse logistics categories. This framework was used to set the structure for the decision making illustrative example.

In addition, sensitivity analysis showed the robustness of the results. The results were relatively robust in terms of rankings and information content. These results can help enable organizations seeking to green their supply chain to use this methodology. Although the proposed model was illustrated for a green manufacturing organization and supply chain process, the methodology can also be easily applied to other decision problems by using a set of relevant attributes.

Although there are multiple contributions associated with this study and methodology, limitations do exist. The green supply chain flexibility framework and methodology was introduced through a conceptual illustrative example, not an actual practical application. A real world application is necessary to help identify and address managerial and behavioral concerns.

Although, green supply chain managers should be encouraged to maintain this type of data, not only for application of this methodology, but for the general future management of their organization, it is not an easy task. In some circumstances, missing or incomplete data plays a key role in evaluation, dealing with missing data will be required. This situation is especially true for green and environmental dimensions, such as the greenness of products, materials, where data is not well structured and may be derived from many sources and stakeholders in the supply chain process. Fuzzy and incomplete data in the evaluation can be overcome using this method.

Another limitation is that the amount of calculations may increase significantly for the proposed method, especially at step 3. This increase in the number of calculations can limit the efficiency of the proposed methodology. Although software for rough set methodologies is available for use, this feature limits the application of the proposed method. Future research can focus on making the methodology more efficient by identifying simpler heuristics or algorithms to compute neighborhood relationships within rough set.

Overall, the multi-step MCDM methodology can support IS program selection for green supply chain management flexibility improvement. Advancing knowledge into green flexibility performance will also advance the research and practice of green supply chain management and minimize complexity. These formal models are necessary for advancing both environmental and operational performance of organizations. 


\section{Acknowledgements}

This work is supported by the National Natural Science Foundation of China Project (71472031, 71772032).

\section{References}

Agarwal, A., Shankar, R., \& Tiwari, M. K. (2006). Modeling the metrics of lean, agile and leagile supply chain: An ANP-based approach. European Journal of Operational Research, 173(1), 211-225. https://doi.org/10.1016/j.ejor.2004.12.005

Bai, C., \& Sarkis, J. (2017). Improving green flexibility through advanced manufacturing technology investment: Modeling the decision process. International Journal of Production Economics, 188, 86-104. https://doi.org/10.1016/j.ijpe.2017.03.013

Bai, C., \& Sarkis, J. (2010). Integrating sustainability into supplier selection with grey system and rough set methodologies. International Journal of Production Economics, 124(1), 252-264. https://doi.org/10.1016/j.ijpe.2009.11.023

Bai, C., \& Sarkis, J. (2013a). Flexibility in reverse logistics: a framework and evaluation approach. Journal of Cleaner Production, 47, 306-318. https://doi.org/10.1016/j.jclepro.2013.01.005

Bai, C., \& Sarkis, J. (2013b). Green information technology strategic justification and evaluation. Information Systems Frontiers, 15(5), 831-847. https://doi.org/10.1007/s10796-013-9425-x

Bai, C., Dhavale, D., \& Sarkis, J. (2016). Complex investment decisions using rough set and fuzzy cmeans: An example of investment in green supply chains. European Journal of Operational Research, 248(2), 507-521. https://doi.org/10.1016/j.ejor.2015.07.059

Bai, C., Fahimnia, B., \& Sarkis, J. (2015b). Sustainable transport fleet appraisal using a hybrid multiobjective decision making approach. Annals of Operations Research, 250(2), 309-340. https://doi.org/10.1007/s10479-015-2009-Z

Bai, C., Sarkis, J., \& Dou, Y. (2015a). Corporate sustainability development in China: review and analysis. Industrial Management \& Data Systems, 115(1), 5-40. https://doi.org/10.1108/IMDS-09-2014-0258

Bai, C., Sarkis, J., Wei, X., \& Koh, L. (2012). Evaluating ecological sustainable performance measures for supply chain management. Supply Chain Management: An International Journal, 17(1), 78-92. https://doi.org/10.1108/13598541211212221

Blome, C., Schoenherr, T., \& Eckstein, D. (2014). The impact of knowledge transfer and complexity on supply chain flexibility: A knowledge-based view. International Journal of Production Economics, 147(Part B), 307-316. https://doi.org/10.1016/j.ijpe.2013.02.028

Blome, C., Schoenherr, T., \& Rexhausen, D. (2013). Antecedents and enablers of supply chain agility and its effect on performance: a dynamic capabilities perspective. International Journal of Production Research, 51(4), 1295-1318. https://doi.org/10.1080/00207543.2012.728011

Braunscheidel, M. J., \& Suresh, N. C. (2009). The organizational antecedents of a firm's supply chain agility for risk mitigation and response. Journal of Operations Management, 27(2), 119-140. https://doi.org/10.1016/j.jom.2008.09.006

Cachon, G. P., \& Fisher, M. (2000). Supply chain inventory management and the value of shared information. Management Science, 46(8), 1032-1048. https://doi.org/10.1287/mnsc.46.8.1032.12029

Chandra, C., \& Grabis, J. (2009). Role of flexibility in supply chain design and modeling - Introduction to the special issue. Omega, 37(4), 743-745. https://doi.org/10.1016/j.omega.2008.07.003 
Chen, S. J., \& Hwang, C. L. (1992). Fuzzy multiple attribute decision making methods, In Fuzzy multiple attribute decision making (pp. 289-486). Berlin, Heidelberg: Springer. https://doi.org/10.1007/978-3-642-46768-4_5

Chryssolouris, G., \& Lee, M. (1992). An assessment of flexibility in manufacturing systems. Manufacturing Review, 5(2), 105-116.

Chuu, S. J. (2011). Interactive group decision-making using a fuzzy linguistic approach for evaluating the flexibility in a supply chain. European Journal of Operational Research, 213(1), 279-289. https://doi.org/10.1016/j.ejor.2011.03.022

Das, K. (2011). Integrating effective flexibility measures into a strategic supply chain planning model. European Journal of Operational Research, 211(1), 170-183. https://doi.org/10.1016/j.ejor.2010.12.006

Deng, J. L. (1989). Introduction to grey system theory. The Journal of Grey System, 1(1), 1-24.

Duclos, L. K., Vokurka, R. J., \& Lummus, R. R. (2003). A conceptual model of supply chain flexibility. Industrial Management \& Data Systems, 103(6), 446-456. https://doi.org/10.1108/02635570310480015

Esmaeilikia, M., Fahimnia, B., Sarkis, J., Govindan, K., Kumar, A., \& Mo, J. (2016). A tactical supply chain planning model with multiple flexibility options: an empirical evaluation. Annals of Operations Research, 244(2), 429-454. https://doi.org/10.1007/s10479-013-1513-2

Fayezi, S., Zutshi, A., \& O’Loughlin, A. (2015). How Australian manufacturing firms perceive and understand the concepts of agility and flexibility in the supply chain. International Journal of Operations \& Production Management, 35(2), 246-281. https://doi.org/10.1108/IJOPM-12-2012-0546

Fisher, M. L. (1997). What is the right supply chain for your product?. Harvard Business Review, 75, 105-117.

Garavelli, A. C. (2003). Flexibility configurations for the supply chain management. International Journal of Production Economics, 85(2), 141-153. https://doi.org/10.1016/S0925-5273(03)00106-3

Gligor, D. M., Esmark, C. L., \& Holcomb, M. C. (2015). Performance outcomes of supply chain agility: When should you be agile?. Journal of Operations Management, 33, 71-82. https://doi.org/10.1016/j.jom.2014.10.008

Golden, W., \& Powell, P. (1999). Exploring inter-organisational systems and flexibility in Ireland: a case of two value chains. International Journal of Agile Management Systems, 1(3), 169-176. https://doi.org/10.1108/14654659910296544

Gong, M., Tan, K. H., Pawar, K., Wong, W. P., \& Tseng, M. L. (2015). Information communication technology and sustainable food supply chain: a resource-based analysis. International Journal of Business Performance and Supply Chain Modelling, 7(3), 233-255. https://doi.org/10.1504/IJBPSCM.2015.071611

Gosain, S., Malhotra, A., \& El Sawy, O. A. (2004). Coordinating for flexibility in e-business supply chains. Journal of Management Information Systems, 21(3), 7-45. https://doi.org/10.1080/07421222.2004.11045816

Gosling, J., Purvis, L., \& Naim, M. M. (2010). Supply chain flexibility as a determinant of supplier selection. International Journal of Production Economics, 128(1), 11-21. https://doi.org/10.1016/j.ijpe.2009.08.029

Hervani, A. A., Helms, M. M., \& Sarkis, J. (2005). Performance measurement for green supply chain management. Benchmarking: An International Journal, 12(4), 330-353. https://doi.org/10.1108/14635770510609015

Hu, Q., Yu, D., \& Xie, Z. (2008b). Neighborhood classifiers. Expert Systems with Applications, 34(2), 866-876. https://doi.org/10.1016/j.eswa.2006.10.043

$\mathrm{Hu}$, Q., Yu, D., Liu, J., \& Wu, C. (2008a). Neighborhood rough set based heterogeneous feature subset selection. Information Sciences, 178(18), 3577-3594. https://doi.org/10.1016/j.ins.2008.05.024 
Jin, Y., Vonderembse, M., Ragu-Nathan, T. S., \& Smith, J. T. (2014). Exploring relationships among IT-enabled sharing capability, supply chain flexibility, and competitive performance. International Journal of Production Economics, 153, 24-34. https://doi.org/10.1016/j.ijpe.2014.03.016

Karsak, E. E. (2002). Distance-based fuzzy MCDM approach for evaluating flexible manufacturing system alternatives. International Journal of Production Research, 40(13), 3167-3181. https://doi.org/10.1080/00207540210146062

Koste, L. L., Malhotra, M. K., \& Sharma, S. (2004). Measuring dimensions of manufacturing flexibility. Journal of Operations Management, 22(2), 171-196. https://doi.org/10.1016/j.jom.2004.01.001

Kumar, V., Fantazy, K. A., Kumar, U., \& Boyle, T. A. (2006). Implementation and management framework for supply chain flexibility. Journal of Enterprise Information Management, 19(3), 303-319. https://doi.org/10.1108/17410390610658487

Liang, J., Shi, Z., Li, D., \& Wierman, M. J. (2006). Information entropy, rough entropy and knowledge granulation in incomplete information systems. International Journal of General Systems, 35(6), 641-654. https://doi.org/10.1080/03081070600687668

Liu, H., Ke, W., Wei, K. K., \& Hua, Z. (2013). The impact of IT capabilities on firm performance: The mediating roles of absorptive capacity and supply chain agility. Decision Support Systems, 54(3), 1452-1462. https://doi.org/10.1016/j.dss.2012.12.016

Luo, D., \& Wang, X. (2012). The multi-attribute grey target decision method for attribute value within three-parameter interval grey number. Applied Mathematical Modelling, 36(5), 1957-1963. https://doi.org/10.1016/j.apm.2011.07.074

Luo, D., Wang, X., \& Song, B. (2013). Multi-attribute decision-making methods with three-parameter interval grey number. Grey Systems: Theory and Application, 3(3), 305-315. https://doi.org/10.1108/GS-08-2013-0021

Malhotra, M. K., \& Mackelprang, A. W. (2012). Are internal manufacturing and external supply chain flexibilities complementary capabilities?. Journal of Operations Management, 30(3), 180-200. https://doi.org/10.1016/j.jom.2012.01.004

Martínez Sánchez, A., \& Pérez Pérez, M. (2005). Supply chain flexibility and firm performance: a conceptual model and empirical study in the automotive industry. International Journal of Operations \& Production Management, 25(7), 681-700. https://doi.org/10.1108/01443570510605090

MendonçaTachizawa, E., \& Giménez Thomsen, C. (2007). Drivers and sources of supply flexibility: an exploratory study. International Journal of Operations \& Production Management, 27(10), 11151136. https://doi.org/10.1108/01443570710820657

Merschmann, U., \& Thonemann, U. W. (2011). Supply chain flexibility, uncertainty and firm performance: an empirical analysis of German manufacturing firms. International Journal of Production Economics, 130(1), 43-53. https://doi.org/10.1016/j.ijpe.2010.10.013

Moon, K. K. L., Yi, C. Y., \& Ngai, E. W. T. (2012). An instrument for measuring supply chain flexibility for the textile and clothing companies. European Journal of Operational Research, 222(2), 191-203. https://doi.org/10.1016/j.ejor.2012.04.027

More, D. S., \& Babu, A. S. (2011). Supply chain flexibility: a risk management approach. International Journal of Business Innovation and Research, 5(3), 255-279. https://doi.org/10.1504/IJBIR.2011.040098

Morlok, E. K., \& Chang, D. J. (2004). Measuring capacity flexibility of a transportation system. Transportation Research Part A: Policy and Practice, 38(6), 405-420. https://doi.org/10.1016/j.tra.2004.03.001

Naim, M. M., Potter, A. T., Mason, R. J., \& Bateman, N. (2006). The role of transport flexibility in logistics provision. The International Journal of Logistics Management, 17(3), 297-311.

https://doi.org/10.1108/09574090610717491 
Nakahara, Y., Sasaki, M., \& Gen, M. (1992). On the linear programming problems with interval coefficients. Computers \& Industrial Engineering, 23(1), 301-304.

https://doi.org/10.1016/0360-8352(92)90121-Y

Ngai, E. W., Chau, D. C., \& Chan, T. L. A. (2011). Information technology, operational, and management competencies for supply chain agility: Findings from case studies. The Journal of Strategic Information Systems, 20(3), 232-249. https://doi.org/10.1016/j.jsis.2010.11.002

Opricovic, S., \& Tzeng, G. H. (2004). Compromise solution by MCDM methods: A comparative analysis of VIKOR and TOPSIS. European Journal of Operational Research, 156(2), 445-455. https://doi.org/10.1016/S0377-2217(03)00020-1

Pawlak, Z. (1982). Rough sets. International Journal of Computer \& Information Sciences, 11(5), 341-356. https://doi.org/10.1007/BF01001956

Samuel, K. E., \& Spalanzani, A. (2009). Developing collaborative competencies within supply chains. International Journal of Information Technology and Management, 8(2), 146-160. https://doi.org/10.1504/IJITM.2009.023297

Seebacher, G., \& Winkler, H. (2014). Evaluating flexibility in discrete manufacturing based on performance and efficiency. International Journal of Production Economics, 153, 340-351. https://doi.org/10.1016/j.ijpe.2014.03.018

Seebacher, G., \& Winkler, H. (2015). A capability approach to evaluate supply chain flexibility. International Journal of Production Economics, 167, 177-186. https://doi.org/10.1016/j.ijpe.2015.05.035

Sethi, A. K., \& Sethi, S. P. (1990). Flexibility in manufacturing: a survey. International Journal of Flexible Manufacturing Systems, 2(4), 289-328. https://doi.org/10.1007/BF00186471

Slack, N. (1983). Flexibility as a manufacturing objective. International Journal of Operations \& Production Management, 3(3), 4-13. https://doi.org/10.1108/eb054696

Stevenson, M., \& Spring, M. (2007). Flexibility from a supply chain perspective: definition and review. International Journal of Operations \& Production Management, 27(7), 685-713.

https://doi.org/10.1108/01443570710756956

Stevenson, M., \& Spring, M. (2009). Supply chain flexibility: an inter-firm empirical study. International Journal of Operations \& Production Management, 29(9), 946-971. https://doi.org/10.1108/01443570910986238

Swafford, P. M., Ghosh, S., \& Murthy, N. (2006). The antecedents of supply chain agility of a firm: scale development and model testing. Journal of Operations Management, 24(2), 170-188. https://doi.org/10.1016/j.jom.2005.05.002

Swafford, P. M., Ghosh, S., \& Murthy, N. (2008). Achieving supply chain agility through IT integration and flexibility. International Journal of Production Economics, 116(2), 288-297. https://doi.org/10.1016/j.ijpe.2008.09.002

Tamayo-Torres, J., Gutierrez-Gutierrez, L., \& Ruiz-Moreno, A. (2014). The relationship between exploration and exploitation strategies, manufacturing flexibility and organizational learning: An empirical comparison between Non-ISO and ISO certified firms. European Journal of Operational Research, 232(1), 72-86. https://doi.org/10.1016/j.ejor.2013.06.040

Tang, C., \& Tomlin, B. (2008). The power of flexibility for mitigating supply chain risks. International Journal of Production Economics, 116(1), 12-27. https://doi.org/10.1016/j.ijpe.2008.07.008

Tippins, M. J., \& Sohi, R. S. (2003). IT competency and firm performance: is organizational learning a missing link?. Strategic Management Journal, 24(8), 745-761. https://doi.org/10.1002/smj.337

Tiwari, A. K., Tiwari, A., \& Samuel, C. (2015). Supply chain flexibility: a comprehensive review. Management Research Review, 38(7), 767-792. https://doi.org/10.1108/MRR-08-2013-0194 
Vickery, S., Calantone, R., \& Dröge, C. (1999). Supply chain flexibility: an empirical study. Journal of Supply Chain Management, 35(2), 16-24. https://doi.org/10.1111/j.1745-493X.1999.tb00058.x

Vokurka, R. J., \& O'Leary-Kelly, S. W. (2000). A review of empirical research on manufacturing flexibility. Journal of Operations Management, 18(4), 485-501. https://doi.org/10.1016/S0272-6963(00)00031-0

White, A. E. D. M., Daniel, E. M., \& Mohdzain, M. (2005). The role of emergent information technologies and systems in enabling supply chain agility. International Journal of Information Management, 25(5), 396-410. https://doi.org/10.1016/j.ijinfomgt.2005.06.009

Wilson, D. R., \& Martinez, T. R. (1997). Improved heterogeneous distance functions. Journal of Artificial Intelligence Research, 6, 1-34.

Winkler, H., \& Seebacher, G. (2012). Considerations on a contemporary flexibility approach. Research in Logistics \& Production, 2, 147-161.

Wu, K. J., Tseng, M. L., Chiu, ASF, \& Lim, M. K. (2016). Achieving competitive advantage through supply chain agility under uncertainty: A novel multi-criteria decision-making structure. International Journal of Production Economics, 190, 96-107. https://doi.org/10.1016/j.ijpe.2016.08.027

Yusuf, Y. Y., Gunasekaran, A., Musa, A., Dauda, M., El-Berishy, N. M., \& Cang, S. (2014). A relational study of supply chain agility, competitiveness and business performance in the oil and gas industry. International Journal of Production Economics, 147(Part B): 531-543.

https://doi.org/10.1016/j.ijpe.2012.10.009 